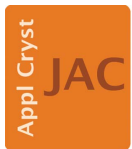

JOURNAL OF

APPLIED

CRYSTALLOGRAPHY

ISSN 1600-5767

Received 29 November 2017

Accepted 14 May 2018

Edited by A. J. Allen, National Institute of Standards and Technology, Gaithersburg, USA

${ }^{1}$ This article will form part of a virtual special issue on advanced neutron scattering instrumentation, marking the 50th anniversary of the journal.

₹ Present addres: Institute of Physical Chemistry, RWTH Aachen University, Landoltweg 2, D-52056 Aachen, Germany.

Keywords: microfluidic devices; small-angle neutron scattering; lab-on-a-chip; closed-face polymer photolithography.

Supporting information: this article has supporting information at journals.iucr.org/j
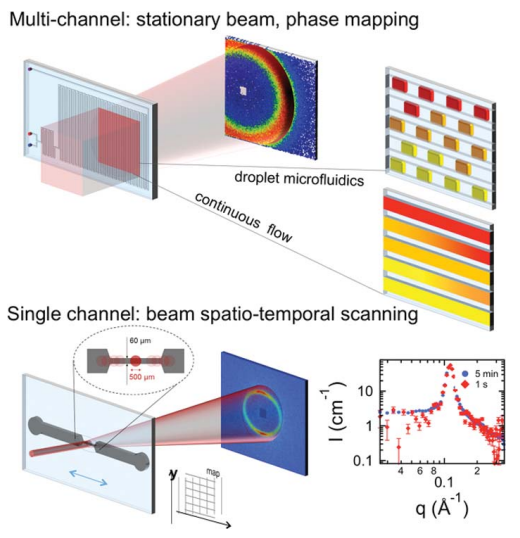

OPEN $\odot$ ACCESS

\section{Microfluidic devices for small-angle neutron scattering ${ }^{1}$}

\author{
Carlos G. Lopez, ${ }^{\mathrm{a}} ¥$ Takaichi Watanabe, ${ }^{\mathrm{a}}$ Marco Adamo, ${ }^{\mathrm{a}, \mathrm{b}}$ Anne Martel, ${ }^{\mathrm{b}}$ Lionel \\ Porcar $^{b}$ and João T. Cabral ${ }^{a *}$
}

${ }^{a}$ Department of Chemical Engineering, Imperial College London, South Kensington Campus, London SW7 2AZ, UK, and b Institut Laue-Langevin, 71 avenue des Martyrs, 38042 Grenoble, France. *Correspondence e-mail: j.cabral@imperial.ac.uk

A comparative examination is presented of materials and approaches for the fabrication of microfluidic devices for small-angle neutron scattering (SANS). Representative inorganic glasses, metals, and polymer materials and devices are evaluated under typical SANS configurations. Performance criteria include neutron absorption, scattering background and activation, as well as spatial resolution, chemical compatibility and pressure resistance, and also cost, durability and manufacturability. Closed-face polymer photolithography between boron-free glass (or quartz) plates emerges as an attractive approach for rapidly prototyped microfluidic SANS devices, with transmissions up to $\sim 98 \%$ and background similar to a standard liquid cell $\left(I \simeq 10^{-3} \mathrm{~cm}^{-1}\right)$. For applications requiring higher durability and/or chemical, thermal and pressure resistance, sintered or etched boron-free glass and silicon devices offer superior performance, at the expense of various fabrication requirements, and are increasingly available commercially.

\section{Introduction}

Microfluidic devices can generate exceptionally precise flow fields and manipulate fluids within length scales from $1 \mathrm{~mm}$ to sub-micrometre (Squires \& Quake, 2005), approaching dimensions characteristic of common soft-matter structures such as vesicles or aggregates. The time scales on which shear can be applied are commensurate with the relaxation times of many systems, including solutions of polymers or colloids. In this sense, the time and length scales of microfluidics and soft matter or complex fluids 'share a common physicochemical parameter space' (Bartolo \& Aarts, 2012). Furthermore, microfluidic formulators enable the generation of vast sample arrays in segmented or continuous flows with minute sample volumes (pico- to nanolitres), valuable for the composition or phase mapping of mixtures, and they are amenable to coupling with scattering or diffraction (Zheng et al., 2003; Zhou et al., 2008; Schwemmer et al., 2016; Pham et al., 2017).

Small-angle neutron scattering (SANS) is a unique noninvasive probe for the structure and dynamics of soft matter. A variety of flow cells (Eberle \& Porcar, 2012) have been employed to study the structure, rheology and kinetics of soft matter under flow, and representative examples are given in Table 1. The steady increase in SANS neutron flux at both reactor and pulsed sources, primarily due to improved neutron guides, and improvements in detector technology now enable microfluidic SANS experiments, opening a range of possibilities to interrogate simple and complex fluids (Lopez et al., 2015; Adamo et al., 2017, 2018). 
Table 1

Representative flow cells employed with SANS.

\begin{tabular}{|c|c|c|c|}
\hline Method & Flow type & Fabrication material & References \\
\hline \multirow{2}{*}{ Flow-SANS } & Poiseuille & Quartz & Cloke et al. (1996) \\
\hline & Contraction-expansion & Aluminium, sapphire & $\begin{array}{l}\text { Bent, Hutchings et al. (2003), Bent, Richards \& Gough } \\
\text { (2003), Lutz-Bueno et al. (2015) }\end{array}$ \\
\hline Rheo-SANS & Couette & Quartz, aluminium, titanium & $\begin{array}{l}\text { Gurnon } \text { et al. (2014), Takeda et al. (2011), Liberatore et al. } \\
\text { (2006), Gentile } \text { et al. (2011), Egres et al. (2006), Yearley } \\
\text { et al. (2010), Lindner \& Oberthür (1984), Cummins } \\
\text { et al. (1990) }\end{array}$ \\
\hline \multirow[t]{3}{*}{ Stopped-flow and other setups } & Stopped flow & Quartz & Reviewed by Grillo (2009) \\
\hline & Size-exclusion chromatography & Quartz & Jordan et al. (2016) \\
\hline & Flow-through cell & Quartz & Metze et al. (2017), Hayward et al. (2018) \\
\hline
\end{tabular}

While a number of microfabrication techniques for microfluidic SAXS (small-angle X-ray scattering) (Greaves \& Manz, 2005; Ghazal et al., 2016) have been developed (Shastry et al., 1998; Stehle et al., 2013; Merlin et al., 2011; Møller et al., 2013; Skou et al., 2014; With et al., 2014; Beuvier et al., 2015; Rodríguez-Ruiz et al., 2017), these are not directly transposable to neutrons. Neutrons interact with the atomic nucleus itself, which varies significantly between elements and isotopes. In addition to the design and fabrication of traditional SANS cells, which are well established and have been recently reviewed (Bailey, 2003; Barker \& Mildner, 2015), microfabrication methods have additional requirements (notably feature resolution) and generally benefit from rapid prototyping techniques. To date, there has not been a systematic examination of microdevice fabrication materials and methods for microfluidic SANS, which is the purpose of this work.

This paper is organized as follows. We first illustrate recent developments in microfluidic SANS, applied to the phase mapping and flow processing of complex fluids. In order to rationalize the materials and microfabrication evaluation, the basic principles of SANS are outlined, followed by a survey of the suitability of different materials and methods for microdevice fabrication. A number of approaches are considered, and recommendations are made for three that show particular promise. We conclude with an assessment of the compatibility of various systems with microfludic SANS, estimating the feasibility of experimental measurements.

\section{Opportunities for microfluidics and SANS}

Fig. 1 illustrates current capabilities of microfluidic SANS, for both equilibrium (top) and non-equilibrium (bottom row) studies of simple and complex fluids. The former include mapping of the composition space of mixtures to establish thermodynamic phase diagrams, and determination of the shapes and interactions of objects (colloids, micelles, aggregates etc.) in solution. These experiments are generally implemented by continually varying input compositions and acquiring SANS data at a fixed position in a microdevice, often overilluminating several channels, in both continuous (Adamo et al., 2017) and droplet flows (Adamo et al., 2018), as shown in Fig. 1(a). In these experiments, a square beam of $1 \times$ $1 \mathrm{~cm}$ was employed, illuminating $\sim 16$ channels. The beam illuminates a location along the microdevice selected to ensure mixing of various inputs but limited compositional dispersion, defining a (time-varying) system composition with prescribed precision. Given the comparatively large sample volume probed, sub-second acquisition times are easily attainable, as illustrated with a micellar solution in Fig. 1(b), since the effective sample volume reduction is modest. For instance, the illuminated channel area is typically $50-70 \%$ of the beam footprint (the remainder being occupied by the device matrix), and microchannel depths are typically $100-1000 \mu \mathrm{m}$. As a result, sample volumes are approximately $5-50 \%$ of those of a common liquid cell, requiring a modest adjustment of SANS measurement times. Rapid and precise contrast matching measurements, and systematic dilution or composition scans in $\sim 10 \mathrm{~min}$ (total) time scales, are readily possible (Figs. $1 c$ and $1 d$ ), circumventing the traditional, sequential and timeconsuming preparation of discrete samples, loading of cells and use of sample changers. Further, microfluidic SANS also allows adaptive scanning of parameter space (Adamo et al., 2017) and possible feedback and optimization loops. In this mode, the device functions as an automated formulator, removing the sample making/loading/washing bottleneck.

Microfluidic SANS also provides unique opportunities in flow-SANS, to elucidate the mechanisms and kinetics of molecular and mesoscopic processes underpinning the flow response, assembly and metastability in complex and biological fluids. The approach is illustrated in the bottom row of Fig. 1. These studies often benefit from the rapid prototyping of microdevices to generate a variety of precise flow fields of tunable type and magnitude, for instance in the microfluidic four-roll mill (Hudson et al., 2004; Lee et al., 2007), and emulate flows relevant to manufacturing processes or porous media (Vasudevan et al., 2010) as well as to fundamental rheology. In order to spatio-temporally probe the response of a complex fluid to a given flow field, the beam footprint should be small 'enough' to enable mapping by scanning device positions under steady-state conditions, employing an $x y z \theta$ 


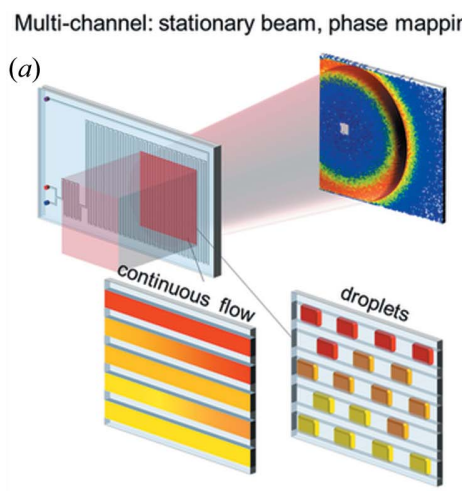

Single channel: beam spatio-temporal scanning

(e)

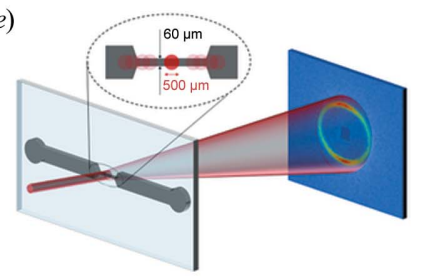

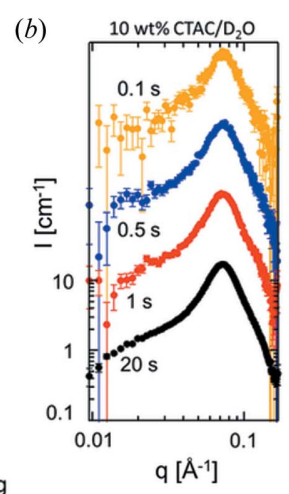

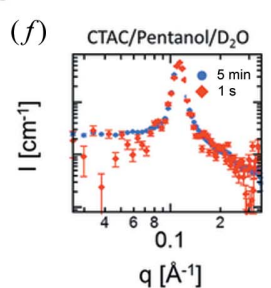

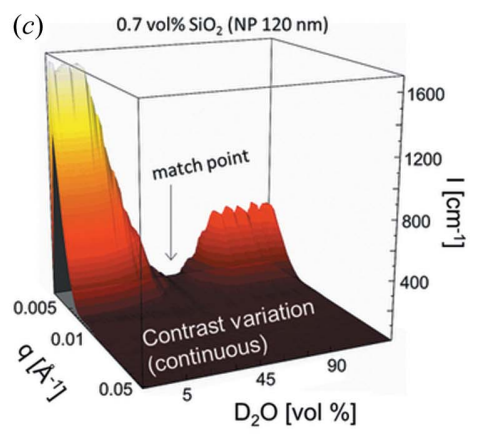
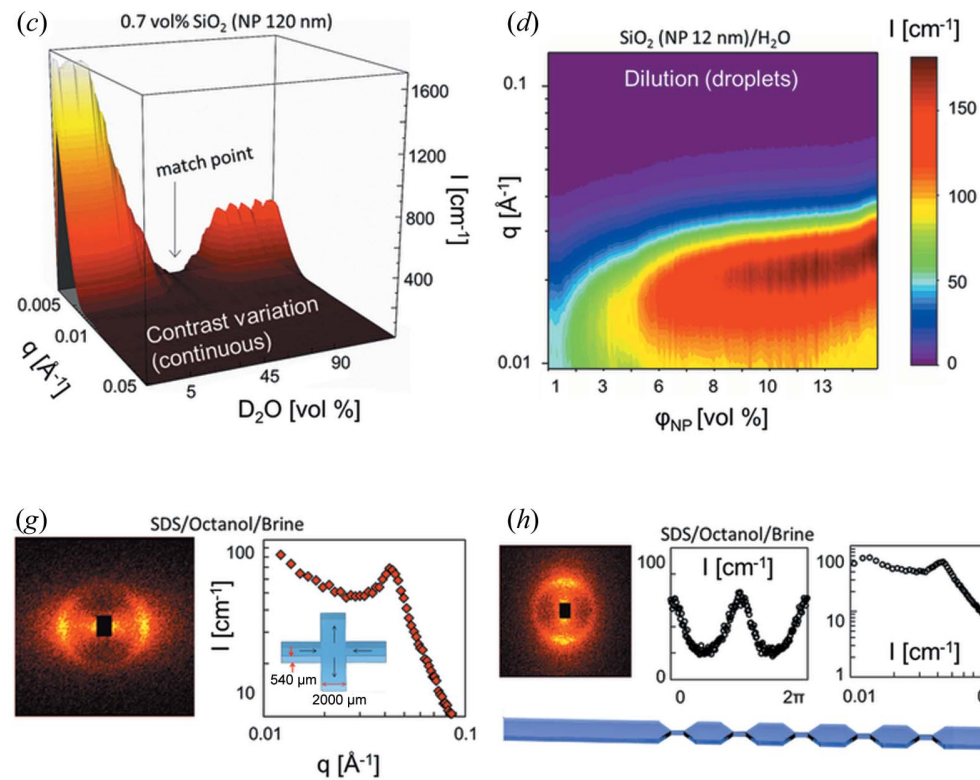

(h)

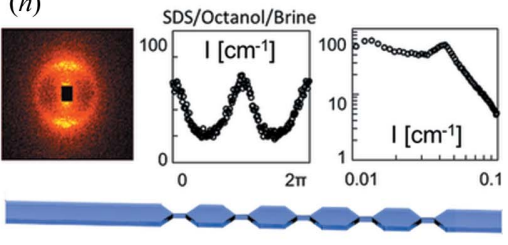

Figure 1

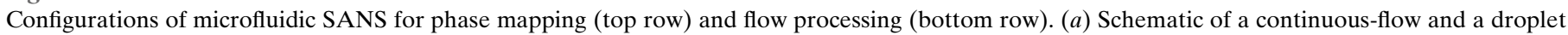

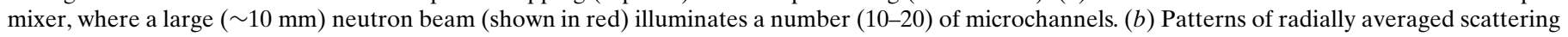

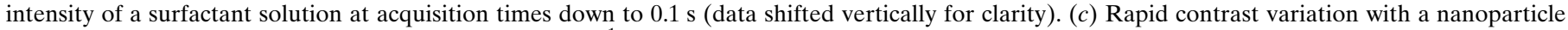

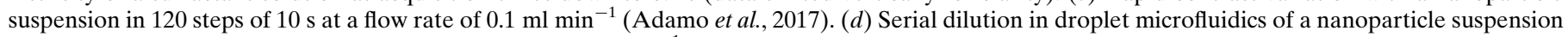

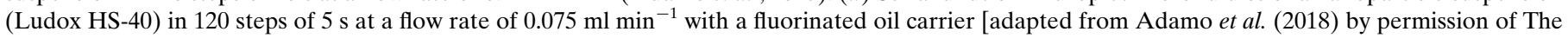

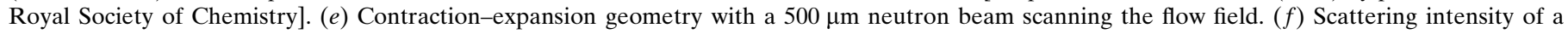

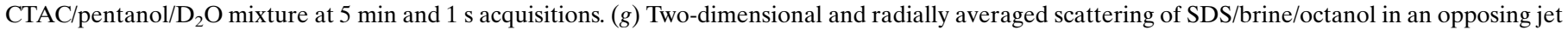

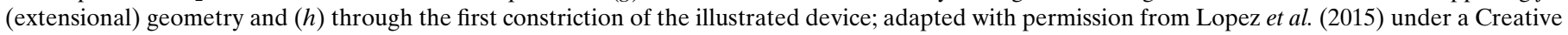
Commons Attribution 4.0 International License, https://creativecommons.org/licenses/by/4.0/.

stage. Neutron beams of typically hundreds of micrometres are employed, and sub-beam-footprint resolution is possible. Given the strong reduction in flux, this approach is only compatible with strongly scattering (e.g. highly ordered) fluids. Fig. 1(e) illustrates a contraction-expansion geometry for which scattering from a single $\sim 50 \mu \mathrm{m}$ channel was attainable with a concentrated surfactant solution, shown in Fig. 1( $f)$, and acquisition times down to $1 \mathrm{~s}$ per spectrum. For instance, cross-slot (and four-roll mill) and periodic constriction geometries, shown in Figs. $1(g)$ and $1(h)$, can be fabricated and the effect of flow quantified, beyond the traditional flow geometries accessible, as introduced in Table 1. Data analysis and interpretation must take into account the fluid velocity profile (e.g. parabolic or plug flow) within the microchannel, which normally requires ancillary flow measurements (Martin et al., 2016; Poulos et al., 2016; Weston et al., 2018). Since multiple shear rates are effectively weighted in the data, systematic variation of channel geometry and flow rate provides new opportunities for rheo-SANS.

Equipped with the ability to label multicomponent systems selectively, we expect microfluidic SANS to build upon the accomplishments of microfluidic SAXS over the past two decades, for instance in high-throughput screening (Toft et al., 2008), fast transformation kinetics (Pollack \& Doniach, 2009; Graceffa et al., 2013), flow processing (Lutz-Bueno et al., 2016; Silva, 2017) and (bio-)molecular assembly (Koester \& Pfohl, 2012; Bretagne et al., 2017).

\section{Coupling microfluidics and SANS}

SANS probes spatial correlations between ensembles of atomic nuclei on the nanoscale, typically covering a wavenumber range of $0.001 \leq q \leq 0.5 \AA^{-1}$, corresponding to length scales $(d \simeq 2 \pi / q)$ of $1-500 \mathrm{~nm}$. Experiments measure the differential macroscopic scattering cross section of the sample, a product of the form factor $P(q)$ and the structure factor $S(q)$ :

$$
\frac{\mathrm{d} \Sigma}{\mathrm{d} \Omega}=\frac{N}{V} V_{\mathrm{p}}^{2}(\Delta \rho)^{2} P(q) S(q)+B,
$$

where $N / V$ is the number density, $V_{\mathrm{p}}$ is the volume of a solute particle, $(\Delta \rho)^{2}$ is a contrast factor and $B$ is the scattering 'background'. $P(q)$ contains information about the solute's shape and size and $S(q)$ about the spatial correlations between individual scattering species. $\Delta \rho$ can be effectively tuned by selective deuteration, enabling the direct determination of $P(q)$ in concentrated or inter-penetrating systems. Given the number of excellent introductions to SANS and data analysis, we concentrate here on microdevice fabrication aspects.

\subsection{Microfluidic requirements for SANS}

Microdevices for SANS experiments should meet a number of requirements. In short, they must exhibit (i) low neutron absorption; (ii) weak scattering in the experimental wavenumber $q$ range relevant for SANS (approximately 0.001$0.5 \AA^{-1}$ ) compared with the samples of interest; (iii) low 
neutron activation and/or short half-life decay; (iv) chemical compatibility with the sample and ability to withstand the required pressure, typically up to $1-10$ bar (but potentially higher; 1 bar = $100000 \mathrm{~Pa}$ ), without deformation, as required for absolute SANS intensity calibration; (v) feature resolution in the range $\sim 1-1000 \mu \mathrm{m}$; and (vi) compatibility with rapid prototyping techniques (two and three dimensional) if flexible channel design is necessary. Specific applications may have additional requirements, such as oxygen permeability (e.g. for biological samples), surface functionality for prescribed wetting in multiphase flows, or control wall slip.

\subsection{Neutron beam illumination, diaphragms and flux}

Fig. 2 depicts representative illumination configurations for single-channel scanning and channel overillumination, noting that the beam may impinge not only on the microchannel window and sample, but also on the device matrix and/or several microchannels. These non-uniform cross sections, often involving several materials, have significant consequences for data reduction, which becomes non-standard. While a first-order correction simply accounts for the illuminated sample volume, accurate calibration (in relative or absolute units of $\mathrm{cm}^{-1}$ ) must take into account the various contributions to scattering, transmission and absorption from the microdevice components. A detailed description of the data reduction and calibration steps, including useful simplifications and assumptions, is presented in the supporting information.

At high scattering angles, additional geometric data corrections may be necessary since neutrons scattered close to

(a)

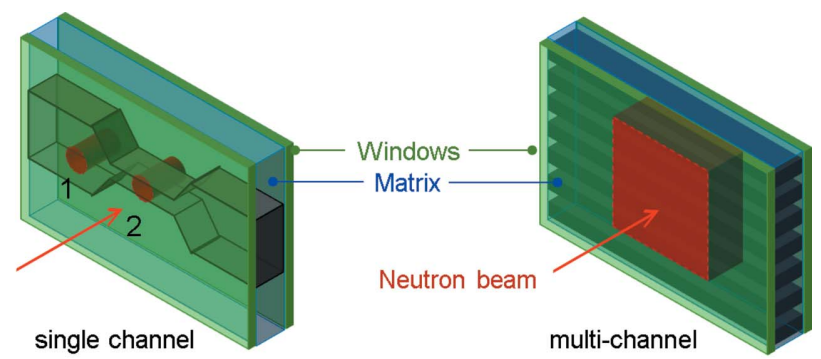

(b)

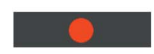

(d)
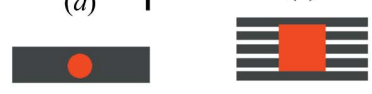

(e)
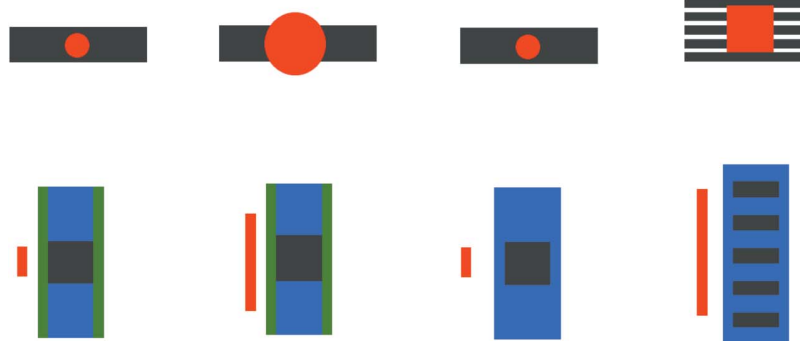

Figure 2

(a) Schematic of microdevice and beam configurations for (left) singlechannel mapping with a beam of $\sim 100-1000 \mu \mathrm{m}$ footprint and (right) overillumination of several channels, with a beam of $\sim 10 \mathrm{~mm}$ footprint. Representative configurations for the beam footprint and channel are given in panels $(b)-(e)$, in both front view (top row) and cross section (bottom row). the edge of a channel will pass through the channel matrix before reaching the detector, and are thus attenuated or scattered in a non-trivial manner. As a rule of thumb, the ratio of channel depth $d$ to width $w$ (or beam diameter, whichever is smaller) should satisfy $4 W / D \lesssim w / d$, where $D$ is the sample-todetector distance and $W$ is the maximum distance between the beam centre and the edge of the detector. For a typical high- $q$ setup $(D \simeq 1.5 \mathrm{~m}, W \simeq 1 \mathrm{~m}), d / w$ greater than $1-3$ should be used. A full offset of the detector (often used to enlarge the $q$ window) can increase this requirement by a factor of 2 .

Neutron focusing optics (e.g. using $\mathrm{MgF}_{2}$ lenses) generally focus the beam at the detector to access lower $q$ values, as required for very small angle scattering, vSANS; focusing at the sample is not suitable as a strategy to decrease the beam size for microfluidics owing to the accompanying increase in beam divergence, which in turn restricts the accessible low- $q$ range (Mildner, 2014). Instead, slits or diaphragms are usually placed as close as possible to the microdevice in order to limit the beam footprint, divergence and air scattering. For a conventional SANS measurement, large circular apertures ( $\sim 12 \mathrm{~mm}$ in diameter) made of absorbing materials $(\mathrm{Cd}, \mathrm{Gd}$, enriched hot-pressed ${ }^{10} \mathrm{~B}_{4} \mathrm{C}$ ) are employed to maximize the illuminated area and thus the scattering signal. Reducing the diameter of the diaphragm, and/or altering its shape, is thus needed to accommodate small samples. Evidently, reducing the beam footprint also reduces the neutron flux, in near proportionality to the area. For instance, reducing a circular beam of $12 \mathrm{~mm}$ diameter to $100 \mu \mathrm{m}$ decreases the neutron flux by $\sim 10^{6}$, limiting the feasibility of some flow-mapping experiments, such as those shown in Fig 1(e). Generally, enriched hot-pressed ${ }^{10} \mathrm{~B}_{4} \mathrm{C}$ is preferred as a manufacturing material as it contains no hydrogen and produces many fewer $\gamma$-rays than the $\mathrm{Cd}$ or $\mathrm{Gd}$ counterparts. These apertures are usually $2 \mathrm{~mm}$ thick and cut by electro-erosion, as ${ }^{10} \mathrm{~B}_{4} \mathrm{C}$ is an extremely hard and brittle material. Slit apertures as small as $50 \mu \mathrm{m}$ can be made to increase the spatial resolution and enable fine scanning. Furthermore, rectangular slits or multislit masks (registered with microchannels) can be desirable to increase the illuminated area and thus the signal and to minimize background scattering, although this requires precise alignment and positional stability.

We next consider different materials and techniques commonly used in microfabrication and their compatibility for microfluidic SANS, accompanied by representative SANS and transmission measurements.

\section{Materials and methods}

\subsection{SANS setup}

Neutron scattering measurements were performed on beamline D22 at the ILL reactor (Institut Laue-Langevin, Grenoble, France) and on the LOQ beamline at the ISIS pulsed source (Rutherford Appleton Laboratory, Oxfordshire, UK). On D22, the wavelength was fixed at a representative $\lambda=$ $6 \AA$, and three sample-to-detector distances were used $(1.2,2.8$ and $5.6 \mathrm{~m}$ ), yielding a $q$ range of $0.009 \leq q \leq 0.6 \AA^{-1}$. 
Acquisition times ranged from 2 to $7 \mathrm{~min}$ for the high- and low- $q$ configurations, respectively. The LOQ data were acquired with a polychromatic incident beam of $\lambda=2-10 \AA$ and (fixed) $4 \mathrm{~m}$ distance, resulting in a $q$ range of $0.009 \leq q \leq$ $0.249 \AA^{-1}$.

\subsection{Materials}

Borosilicate cover slips (thickness $t \simeq 140 \mu \mathrm{m}$ ) and soda lime glass slides $(t \simeq 1 \mathrm{~mm})$ were purchased from Fisher. Quartz slides $(t \simeq 0.44 \mathrm{~mm})$ and fused silica slides $(t \simeq$ $1.1 \mathrm{~mm}$ ) were purchased from $\mathrm{H}$. Baumbach and Co. Ltd. Silicon wafers $(t \simeq 0.34 \mathrm{~mm},\langle 100\rangle$, single-side polished) were purchased from Si-Mat (Germany). A poly(dimethylsiloxane) (PDMS) film $(t \simeq 0.6 \mathrm{~mm})$ was produced by mixing Sylgard 184 elastomer with a curing agent (both obtained from Dow Corning) in a 10:1 weight ratio. The film was then degassed and cured at $348 \mathrm{~K}$ for $1 \mathrm{~h}$. Hydrogenated and deuterated polystyrene (PS) and hydrogenated poly(methyl methacrylate) (PMMA) films $(t \simeq 1 \mathrm{~mm})$ were pressed from standard grades. A thiolene film $(t \simeq 0.54 \mathrm{~mm}$ ) was prepared by photocuring the optical adhesive Norland NOA-81 (purchased from Edmund Optics) with UV light. Kapton film $(t \simeq$ $0.09 \mathrm{~mm}$ ) was obtained from Müller Ahlhorn (Germany). An aluminium slab $(t \simeq 1.2 \mathrm{~mm}$ ) was obtained from the Imperial College London workshop; its scattering pattern was close to that of commercial ( $\sim 4 \mu$ thick) aluminium foil.

Microfluidic experiments with polymer/glass (Lopez et al., 2015) and glass devices (Adamo et al., 2017, 2018) have been reported in detail. The choice of pumps is discussed in the supporting information.

\section{Materials for microfabrication and experimental SANS evaluation}

\subsection{Preliminary considerations}

As a reference, a typical SANS liquid cell, for example the ubiquitous Hellma QS series (made of two $1 \mathrm{~mm}$ thick windows of Suprasil quartz), exhibits a neutron transmission of $\sim 96 \%$ (at $\lambda=6 \AA$ ) and a scattering intensity of $\sim 5 \times$ $10^{-3} \mathrm{~cm}^{-1}$. Fig. S4 in the supporting information summarizes the neutron absorption, transmission and scattering intensity for the most abundant elements, excluding rare earths, noble gases and highly reactive elements, but including major industrial elements and common precious metals (Ag and $\mathrm{Au}$ ). Most low atomic number $(Z \lesssim 40)$ elements yield minimal neutron absorption, except for lithium, boron and cobalt. Hydrogen has a large incoherent cross section and scatters strongly, so its content must be minimized. In addition, crystalline materials with characteristic repeat distances $d \geq 12$ $15 \AA$, and thus exhibiting pronounced structural peaks (at $q^{*}=$ $2 \pi / d$ ), should be avoided. Polycrystalline materials will also scatter in the low- $q$ region owing to grain boundary interfaces (generally isotropically). Otherwise, a range of elements and materials would appear to yield reasonably high-quality SANS cells $(T \gtrsim 96 \%)$ in the high- $q$ region, in particular for microdevices with sufficiently thin windows $(\lesssim 100 \mu \mathrm{m})$.

\subsection{Transmission}

Fig. 3 shows the transmission for different classes of materials used in the fabrication of microdevices, and specific values are compiled in Table $\mathrm{S} 2$ in the supporting information. In addition, the thickness required for microfabrication must be considered and thus we also estimate (bottom row) the transmission ranges of corresponding devices. For the different glasses, we assume the device thicknesses of our fabricated devices described in $\S 6$; for polymers such as PS, PMMA and bisphenol-A polycarbonate (PC), we assume two windows of $200 \mu \mathrm{m}$ each (Metwally et al., 2012; Dhouib et al., 2009); and $t=250 \mu \mathrm{m}$ for thiolene (Brennich et al., 2011).

Inorganic glasses generally show high transmission, except borosilicate glass, for which thin $(\sim 100 \mu \mathrm{m})$ windows are thus required. Polymers show a transmission of $\sim 0.6 \pm 0.1$ for $1 \mathrm{~mm}$ thick slabs, which translates to device transmissions of $\sim 0$. Kapton devices with thin walls (5-50 $\mu$; Evans et al., 2007; Trebbin et al., 2013; Catalano et al., 2014) exhibit high transmissions, of the order of that of a Hellma cell. Deuterated polymers would also yield high transmissions for a typical thickness of $200 \mu \mathrm{m}$ but are comparatively costly. Materials such as silicon and aluminium, with minimal neutron absorption (even for a thickness $\sim 1 \mathrm{~cm}$ ), yield effectively $100 \%$ transmission for microdevices. Nickel, although a strong absorber, can be used to fabricate extremely thin devices $(2 \times$ $10 \mu \mathrm{m}$ ), thus yielding a transmission of $\sim 1$. Taking the high transmission $T=96 \%$ of a Hellma cell as a reference, the window thicknesses required for a microdevice of equivalent transmission are compiled in Table S2 in the supporting information. Despite the significant differences in transmission, no class of material emerges as incompatible for microdevices for SANS.

\subsection{Neutron activation}

Prolonged exposure to neutrons may induce considerable radioactivity in materials, which must decay to safe levels to enable handling, for instance when changing samples or upon completion of an experiment. Low activation and/or a short decay half-life are thus desirable for a microdevice material. While elements $\mathrm{H}, \mathrm{C}, \mathrm{N}$ and $\mathrm{O}$, constituents of polymeric

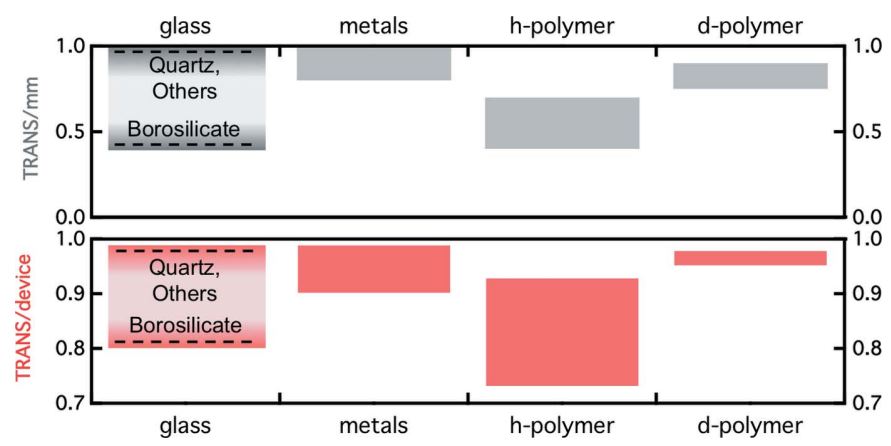

Figure 3

The range of neutron transmissions for different classes of material. The top panel shows the transmission $(T)$ per $1 \mathrm{~mm}$ of material, and the bottom panel shows the estimated transmission of a microdevice with a likely thickness $t_{\mathrm{D}}$ (detailed in the text). 
Table 2

Decay times to $0.1 \mathrm{nCi}$ radioactivity for different materials, masses and exposure times.

Values are calculated for a reference flux of $10^{8}$ neutrons $\mathrm{cm}^{-2} \mathrm{~s}^{-1}$, employing the NIST neutron activation calculator (NIST, 2017).

\begin{tabular}{|c|c|c|c|c|c|c|}
\hline \multirow[b]{5}{*}{ Material } & \multicolumn{6}{|c|}{ Mass (g) } \\
\hline & \multicolumn{2}{|c|}{1} & \multicolumn{2}{|c|}{$10^{-3}$} & \multicolumn{2}{|c|}{$5 \times 10^{-5}$} \\
\hline & \multicolumn{6}{|c|}{ Exposure time (h) } \\
\hline & 1 & 10 & 1 & 10 & 1 & 10 \\
\hline & \multicolumn{6}{|c|}{ Decay time } \\
\hline Copper & $8 \mathrm{~d}$ & $10 \mathrm{~d}$ & $3 \mathrm{~d}$ & $4 \mathrm{~d}$ & $14 \mathrm{~h}$ & $2.2 \mathrm{~d}$ \\
\hline Nickel & $1 \mathrm{~d}$ & $18 \mathrm{y}$ & - & $5 \mathrm{~h}$ & - & - \\
\hline Cobalt & $38 \mathrm{y}$ & $56 \mathrm{y}$ & $2 \mathrm{~h}$ & $3 y$ & $2 \mathrm{~h}$ & $2 \mathrm{~h}$ \\
\hline Titanium & $1 \mathrm{~h}$ & $1 \mathrm{~h}$ & $10 \mathrm{~min}$ & $10 \mathrm{~min}$ & - & - \\
\hline Zinc & $2 y$ & $5 \mathrm{y}$ & $4 \mathrm{~h}$ & $9 \mathrm{~h}$ & - & $1 \mathrm{~h}$ \\
\hline Iron & $1 \mathrm{y}$ & $10 \mathrm{y}$ & - & - & - & - \\
\hline Aluminium & $1 \mathrm{~h}$ & $1 \mathrm{~h}$ & - & - & - & - \\
\hline Palladium & 2 months & 4 months & $2 \mathrm{~d}$ & $4 \mathrm{~d}$ & - & $2 \mathrm{~d}$ \\
\hline Chromium & 7 months & $1 \mathrm{y}$ & - & 1 month & - & - \\
\hline $\mathrm{SiO}_{2}$ & $20 \mathrm{~h}$ & $1 \mathrm{~d}$ & - & - & - & - \\
\hline $\mathrm{Si}$ & $23 \mathrm{~h}$ & $1 \mathrm{~d}$ & - & $1 \mathrm{~h}$ & - & - \\
\hline Borosilicate & $20 \mathrm{~h}$ & $1 \mathrm{~d}$ & - & - & - & - \\
\hline h-PMMA/d-PMMA & - & - & - & - & - & - \\
\hline
\end{tabular}

materials, are intrinsically safe, $1 \mathrm{~g}$ of $\mathrm{Al}$, sapphire $\left(\mathrm{Al}_{2} \mathrm{O}_{3}\right)$ or titanium will typically decay to safe levels within approximately $1 \mathrm{~h}$, and the same mass of $\mathrm{Si}$ or $\mathrm{SiO}_{2}$ (e.g. quartz or fused silica) requires approximately $1 \mathrm{~d}$ after a reference $10 \mathrm{~h}$ exposure at $10^{8}$ neutrons $\mathrm{cm}^{-2} \mathrm{~s}^{-1}$. By contrast, $\mathrm{Cu}$ would require a few days, $\mathrm{Zn}$ and $\mathrm{Fe}$ a few years, and $\mathrm{Ni}$ and $\mathrm{Co}$ decades, under identical conditions (NIST, 2017). These estimates correspond to thicknesses of approximately $1 \mathrm{~mm}(\rho \simeq$ $\left.10 \mathrm{~g} \mathrm{~cm}^{-3}\right)$ to $10 \mathrm{~mm}\left(\rho \simeq 1 \mathrm{~g} \mathrm{~cm}^{-3}\right)$ and a beam footprint of $1 \mathrm{~cm}^{2}$. Evidently, sufficiently thin metal sheet windows with a low mass (if compatible with microfabrication) and smaller beams will eventually yield lower or even imperceptible radioactivity. A configuration with a beam area of $0.25-1 \mathrm{~mm}^{2}$ impinging upon two metal windows of $10-50 \mu \mathrm{m}$ thickness (Chandrasekaran et al., 2003; Lang et al., 2011) results in an irradiated mass of $0.05-1 \mathrm{mg}$ of material (using $\rho \simeq$ $10 \mathrm{~g} \mathrm{~cm}^{-3}$ ), which yields an acceptable decay time for a range of metals, as illustrated in Table 2.

The above estimates for $10 \mathrm{~h}$ exposure, albeit much longer than a single-spectrum acquisition, are reasonable for a series of microfluidic SANS experiments. While the beam is generally open throughout a SANS experiment, it is recommended that the beam is shut off during down-time (e.g. flow stabilization or cleaning) to minimize neutron exposure.

\subsection{Scattering 'background': glasses, polymers, metals and ceramics}

5.4.1. Glass and silicon. A wide range of microfluidic devices are made of glass, quartz and silicon (Dittrich et al., 2006; Iliescu et al., 2012), which can be fabricated by machining and etching techniques, depending on the features required and any cost or time limitations (Lee \& Sundararajan, 2010). Glass and silicon have excellent chemical resistance to most common solvents, as well as good thermal stability, optical transparency (in the case of glass) and Young's modulus in the range of tens of GPa (Lee \& Sundararajan, 2010). Quartz is a standard material for SANS cells, and it therefore seems like an obvious choice for the fabrication of neutron-compatible microdevices. The compositions of different glasses are compiled in Table S1 in the supporting information.
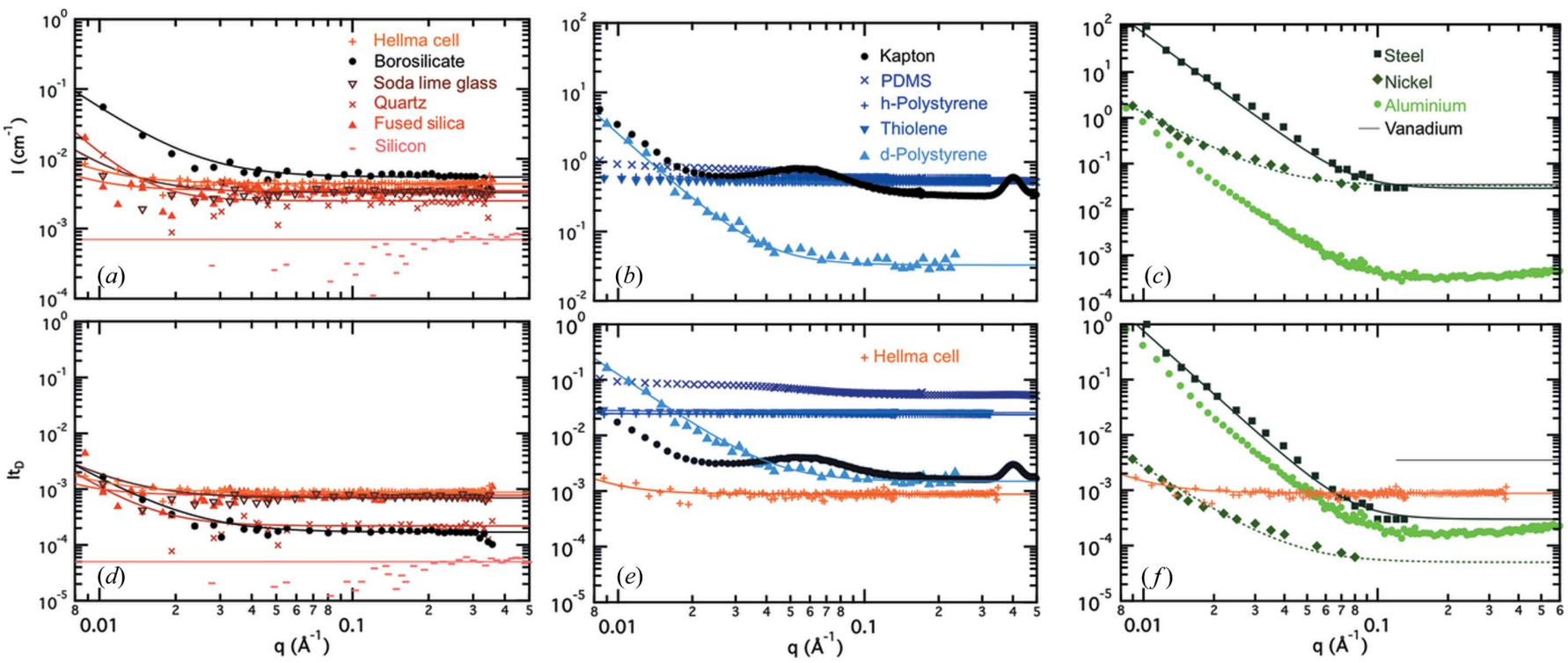

Figure 4

Representative scattering profiles for three classes of material, inorganics, polymers and metals. The top row [panels $(a)-(c)$ ] shows experimental data in absolute units of $\mathrm{cm}^{-1}$, while the bottom row [panels $(d)-(f)$ ] shows $I$ multiplied by the typical thickness $t_{\mathrm{D}}$ (in centimetres) required for a device of the given material. For reference, the scattering from a Hellma cell (orange + symbols) is also included. The window materials (and thicknesses) considered are quartz $(0.44 \mathrm{~mm})$, fused silica $(1.1 \mathrm{~mm})$, soda lime glass $(1.1 \mathrm{~mm})$, borosilicate glass $(0.14 \mathrm{~mm})$, steel $(0.1 \mathrm{~mm})($ Shin et al., 2010$)$, nickel $(10 \mu \mathrm{m} \times 2)$ (Yoo et al., 1982), aluminium $(1 \mathrm{~mm})$ and vanadium $(1 \mathrm{~mm})$ (Imae et al., 2011), shown as a horizontal line. 
Fig. 4 shows experimental scattering profiles for the various glass and silicon specimens, which are compared with selected polymers and metals. The data are presented in two ways: the scattering intensity in absolute units $\left(\mathrm{cm}^{-1}\right)$ is shown in the top graphs. As mentioned above, this can be somewhat misleading, as we are interested in the scattering of the microdevice compared with that of a sample (confined to a given channel depth). The lower panels thus show the same data multiplied by the likely device thickness $t_{\mathrm{D}}$. The scattering signal for all glass and silicon specimens considered is weak compared with that of samples 'compatible' with microfluidic SANS, which should scatter above $\sim 1 \mathrm{~cm}^{-1}$ to enable reasonable acquisition times. Borosilicate exhibits higher scattering (in addition to lower device transmission) and is thus inferior to other glasses. By contrast, silicon is outstanding in this $q$ range and thus even thick devices (of the order of centimetres) would be well suited for SANS. In general, neutron activation is not of concern, provided that the window thicknesses are kept to a minimum (tens to hundreds of micrometres).

5.4.2. Polymers. Polymer-based microdevices are generally inexpensive compared with glass and silicon devices and are amenable to rapid prototyping, i.e. device fabrication within hours of the initial design (Sollier et al., 2011). Polymeric surface properties can be readily tailored by physical patterning or chemical modification (Becker \& Gärtner, 2008), and a range of polymers are optically transparent which facilitates operation. However, polymers generally yield high incoherent signals $\left(\sim 0.5-0.7 \mathrm{~cm}^{-1}\right)$ owing to their high hydrogen content. The absolute scattering profiles of representative polymers are shown in Fig. 4(b), accompanied by their figures of merit $I t_{\mathrm{D}}$ in the panel below, which are consistently above that of a Hellma cell. Polymers are generally classified into elastomers, thermosets and thermoplastics.

Elastomers, polymers with a rubber-like behaviour, exhibit high elasticity (low Young's modulus) and high failure strain. By far the most commonly used elastomer in microfluidics is poly(dimethylsiloxane), PDMS (Whitesides, 2006). Devices are typically fabricated by replication against a mould (often an SU-8 master) and covalently sealed against glass or itself following surface oxidation (McDonald \& Whitesides, 2002). Small feature sizes $(\sim 1 \mu \mathrm{m}$, with sub-0.1 $\mu \mathrm{m}$ fidelity) can be generated with high accuracy in both planar and threedimensional geometries. PDMS also offers good biocompatibility (Bélanger \& Marois, 2001) and is permeable to certain gases, which can be advantageous, e.g. in biology. On the other hand, PDMS suffers from poor solvent compatibility as it is swollen by common organic solvents (Lee et al., 2003). Furthermore, a conventional ( $\sim 1 \mathrm{~cm}$ thick) PDMS device would yield excessive neutron absorption and background scattering for SANS, with $I t_{\mathrm{D}} \simeq 0.5$ and $T \simeq 0.6$. Devising thin PDMS devices is certainly possible (Martin et al., 2016) but, given its elastomeric nature, a thin membrane deforms under pressure, posing a problem in a scattering experiment, as the irradiated volume must be known for absolute intensity calibration.
Thermosets irreversibly cross link into solid networks, often by UV exposure, and include SU-8 (Lee \& Sundararajan, 2010), the thiolene-based NOA-81 (Cabral et al., 2004; Harrison et al., 2004), acrylate formulations (e.g. Khoury et al., 2002) and many others. Thermosets are often used as negative photoresists for master fabrication (open face) as well as for direct microdevice fabrication (closed face) via selective exposure with a photomask and development of the unconverted material. For example, NOA-81 has been used in both closed- and open-face lithography (Harrison et al., 2004; Bartolo et al., 2008), offering broad solvent compatibility (excluding chlorinated solvents; Cygan et al., 2005) and minimum feature sizes of the order of $50 \mu \mathrm{m}$ (Harrison et al., 2004) to a few micrometres (Bartolo et al., 2008). Thermoset polyester (TPE) or polyurethane methacrylate (PUMA) (Sollier et al., 2011) yield devices with small features (down to $\sim 2 \mu \mathrm{m})$ capable of withstanding relatively large pressures ( $\sim 1 \mathrm{MPa}$ or 10 bar $)$.

Thermoplastic polymers, such as PS, PMMA and PC, soften above their glass transition temperature $\left(T_{\mathrm{g}}\right)$ and microdevices can be fabricated by moulding under pressure, or shaped by other techniques including laser ablation. PMMA and cycloolefin-copolymer (COC) devices with wall thicknesses of 130$250 \mu \mathrm{m}$, and polyimide (Kapton) devices with a thickness of $75 \mu \mathrm{m}$, have been fabricated by hot embossing and laser ablation, respectively, and used in SAXS experiments (Metwally et al., 2012; Marmiroli \& Amenitsch, 2012; Dhouib et al., 2009). A disadvantage of polymers such as PMMA is their incompatibility with a number of organic solvents, while Kapton on the other hand offers excellent solvent compatibility. Polyimide film devices have been fabricated by a range of procedures (Evans et al., 2007; Trebbin et al., 2013; Catalano et al., 2014), yielding resolutions from $\sim 1$ to $60 \mu \mathrm{m}$ (Evans et al., 2007) and varying solvent compatibility depending on the additional materials employed. An attractive feature of Kapton devices is the low thickness of the windows, down to $\sim 2 \times 50 \mu \mathrm{m}$.

Highly structured polymers, such as semi-crystalline polymers (or ordered diblock copolymers), can scatter strongly in the high- $q$ region and are therefore not recommended. Fig. 4(b) shows the scattering of five selected polymer systems: hydrogenated PS, PDMS, Kapton and (cross-linked) thiolene, in line with $I(\mathrm{PMMA}) \simeq 0.6 \mathrm{~cm}^{-1}$ and $I$ (polyethylene $) \simeq$ $0.62 \mathrm{~cm}^{-1}$ (Shibayama et al., 2005) which are not shown. While it is possible to employ deuterated polymers to reduce incoherent scattering and absorption, their high(er) cost $\left(\sim 100 \mathrm{USD} \mathrm{g}^{-1}\right)$ and low availability may make this unfeasible. Deuteration yields an incoherent cross section $\sim 15$ times lower that of hydrogenous polymers, resulting in potentially excellent window materials, in particular at high $q$, as shown by the d-PS profile. Hydrogenous polymeric devices therefore perform comparatively poorly for use in microfluidic SANS cells, unless thin-walled polymeric devices are used, provided that they are mechanically robust and enable robust inlet/ outlet connections. Taking an illustrative channel depth of $500 \mu \mathrm{m}$, a device (top and bottom) wall thicknesses of $\sim 25 \mu \mathrm{m}$ would be needed for the channels to scatter similarly to $\mathrm{D}_{2} \mathrm{O}$ 
Table 3

Summary of representative microdevice fabrication approaches along with relevant characteristics.

A reference for the fabrication procedure is provided in the top row. Additional references for specific values are included in the relevant boxes.

\begin{tabular}{|c|c|c|c|c|c|c|}
\hline & Silicon $^{a}$ & Glass/quartz ${ }^{a}$ & Aluminium/glass ${ }^{b}$ & Nickel $^{c}$ & Nickel/silicon ${ }^{d}$ & $\begin{array}{l}\text { NOA-81 closed } \\
\text { lithography }^{e}\end{array}$ \\
\hline Lateral resolution $(\mu \mathrm{m})$ & $1^{a}$ & $1^{a}$ & $100^{f, g}$ & 20 & $20^{d}$ & $50-100^{e}$ \\
\hline$t(\mathrm{~mm})$ & $g$ & $g$ & $5^{g}$ & 0.02 & 0.025 & $0.28-1^{h}$ \\
\hline$I_{\text {back }} t$ & 0.00035 & 0.002 & 0.003 & 0.00006 & 0.00008 & 0.0004 \\
\hline$I\left(q=0.01 \AA^{-1}\right) t$ & 0.00035 & 0.002 & 0.5 & 0.002 & 0.002 & 0.0004 \\
\hline Transmission & 1 & $0.9-0.95$ & 0.8 & 1 & 1 & $0.98 / 0.78$ \\
\hline Solvent compatibility & $++^{j}$ & $++^{j}$ & + & ++ & ++ & $+^{e}$ \\
\hline Equipment requirements & + & + & - & + & - & ++ \\
\hline \multirow[t]{2}{*}{ Notes } & Optically opaque & Commercially available & Commercially available & e Optically opaque & Optically opaque & Compatible with SAXS ${ }^{k}$ \\
\hline & NOA-81 stickers ${ }^{l}$ & Kapton/PDMS ${ }^{m}$ & $\begin{array}{l}\text { Kapton laser } \\
\text { ablation }^{n}\end{array}$ & $\begin{array}{l}\text { h-Polymer hot } \\
\text { embossing }^{\circ}\end{array}$ & $\begin{array}{l}\text { d-Polymer hot } \\
\text { embossing }^{\circ}\end{array}$ & $\mathrm{PDMS}^{p}$ \\
\hline$I\left(q=0.01 \AA^{-1}\right) t$ & 0.02 & 0.03 & 0.06 & 0.015 & 0.06 & 0.09 \\
\hline Transmission & 0.8 & 0.96 & 0.97 & $0.5-0.7$ & 0.97 & 0.6 \\
\hline Cost & ++ & + & ++ & ++ & - & + \\
\hline Rapid prototyping & + & + & - & - & - & + \\
\hline Pressure resistance (bar) & $5^{i}$ & - & + & $10^{t}$ & $10^{t}$ & $3^{v}$ \\
\hline Solvent compatibility & $+{ }^{e}$ & - & ++ & - & - & $-w$ \\
\hline Equipment requirements & + & + & - & - & - & + \\
\hline Notes & $\begin{array}{l}\text { Compatible with } \\
\text { SAXS and light } \\
\text { scattering }\end{array}$ & $\begin{array}{l}\text { Compatible with } \\
\text { SAXS; PDMS can } \\
\text { be replaced by } \\
\text { metal, resolution } \\
\sim 100 \mu \mathrm{m}\end{array}$ & $\begin{array}{l}\text { Compatible with } \\
\text { SAXS }\end{array}$ & $\begin{array}{l}\text { Compatible with } \\
\text { SAXS }\end{array}$ & $\begin{array}{l}\text { Compatible with } \\
\text { SAXS }\end{array}$ & $\begin{array}{l}\text { Deforms under } \\
\text { pressure }\end{array}$ \\
\hline
\end{tabular}

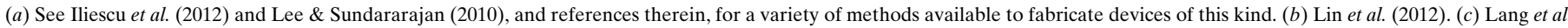

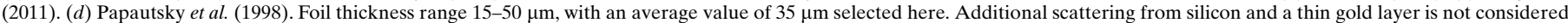

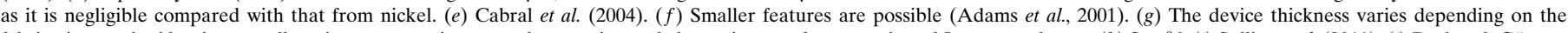

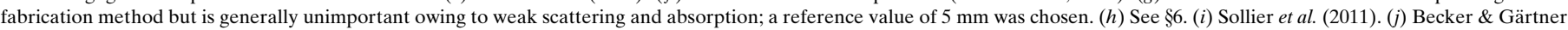
(2008). ( $k$ ) Poulos et al. (2016). ( $($ ) Microfluidic stickers fabricated only with thiolene (Brennich et al., 2011), as considered here, or glass/thiolene/glass devices (Bartolo et al., 2008) (for

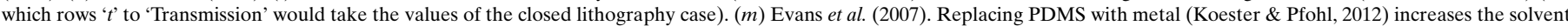

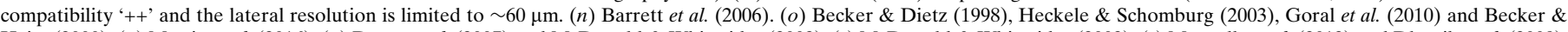

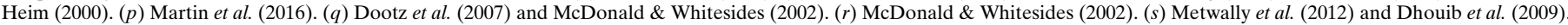

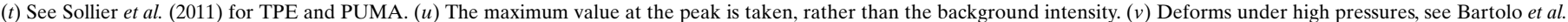
(2008). (w) Lee et al. (2003). (x) Norman et al. (2006).

( $\sim 0.05 \mathrm{~cm}^{-1}$, a relatively weak scatterer). However, a number of 'lab-on-a-foil' polymer devices with windows down to $25 \mu \mathrm{m}$ have been demonstrated in SAXS (Focke et al., 2010; Tsao et al., 2012). Alternatively, given the considerably lower background scattering of various glasses (approximately two orders of magnitude), it seems desirable to construct microdevices with glass windows and polymer matrices, thus combining ease of fabrication and low background, as discussed below.

5.4.3. Metals and ceramics. Metals offer high thermal and electric conductivity, and generally have high Young's modulus, tensile strength and melting point. Gold, nickel and copper are the most commonly used metals in microfabrication (Lee \& Sundararajan, 2010; Lang et al., 2011), but microfluidic devices of several other metals, for example titanium, have also been reported (Lin et al., 2012; Tong et al., 2001; Chandrasekaran et al., 2003; Kobayashi et al., 2008; Zhang et al., 2008). Fig. 4(c) shows the scattering profiles for nickel, aluminium, vanadium and steel, with the expected performance in a device shown by $I t_{\mathrm{D}}$ in the row below. The ability to fabricate mechanically robust thin metal devices leads to generally good neutron cells, in particular in the range $q \geq 0.05 \AA^{-1}$. For example, nickel devices with $10 \mu \mathrm{m}$ thick walls (Lang et al., 2011) are capable of withstanding pressures up to $\sim 6$ bar $(90 \mathrm{psi})$. Aluminium is the weakest scatterer of the metals tested and, even with a $1 \mathrm{~mm}$ reference thickness, it compares favourably with quartz or fused silica in the high- $q$ region $\left(q \geq 0.1 \AA^{-1}\right)$, although its quality decreases at lower $q$ values, reaching the value of $\mathrm{D}_{2} \mathrm{O}$ at $q \simeq 0.02 \AA^{-1}$. However, we note the limited chemical stability of aluminium, and its susceptibility to solutions of varying salt and $\mathrm{pH}$ can impact the surface roughness and composition of the microchannels.

Ceramics are inorganic, hard insulating materials with high melting temperatures and excellent chemical resistance, which have been employed recently for microfabrication (Golonka et al., 2006; Gómez-de Pedro et al., 2010; Schindler \& Roosen, 
2009). For instance, microdevices based on Dupont 951 green tape (http://www.dupont.com; Jones et al., 2000; Rodriguez et al., 2000) have been fabricated by a variety of methods, with wall thicknesses in the 50-250 $\mu \mathrm{m}$ range, with (estimated) high transmission $\left(\sim 0.98 \mathrm{~mm}^{-1}\right)$ and low incoherent and background scattering $\left(I \simeq 0.0002-0.005 \mathrm{~cm}^{-1}\right)$.

Other materials used in microfabrication, such as paper or hydrogels, are not considered here since these do not exhibit high flow resistance and are expected to yield high scattering background.

\section{Microdevice fabrication}

We consider several microfabrication approaches which appear particularly well suited for microfluidic SANS. Polymeric (and hybrid) devices are amenable to rapid prototyping in most university laboratories, are inexpensive, and enable iterations and refinements, which are particularly important for flow-SANS experiments. By contrast, microfabrication in glass or metal, for instance, generally offers more durable devices, able to sustain higher pressures and attractive for repeated or prolonged use, such as in phase mapping. Key features of selected materials and approaches are summarized in Table 3. Amongst these, we highlight three methods that appear particularly well suited to microfluidic SANS.

\subsection{Method 1: closed-face photolithography and reinforce- ment}

Given the low background scattering of (boron-free) glass and quartz and the ease of fabrication of photopolymerization, an attractive fabrication approach consists of so-called 'closedface' lithography, illustrated in Fig. 5. The method consists of the photopolymerization of a UV-curable resin between UVtransparent plates using a photomask, and then the displacement of the unpolymerized liquid to yield the microchannels. The window materials must be transparent to the radiation used for curing (typically UV), and the photoresist must adhere strongly to the window material to withstand pressure. Quartz, fused silica, crown glass and soda lime glass offer good optical and neutron properties and are thus suitable windows. Handling, drilling and port connection require the use of either relatively thick $(\sim 1-1.2 \mathrm{~mm})$ or reinforced thin cover slides $(\sim 100-150 \mu \mathrm{m})$, as described below.

The detailed procedure is illustrated in Fig. 5. Panel I (left) shows the simplest procedure, reported earlier by Harrison et al. (2004) and here employing $\sim 1 \mathrm{~mm}$ boron-free glass (e.g. B270, Schott AG) or quartz plates. Panel II depicts a longer procedure, yielding devices compatible with both SANS and SAXS. The procedure is as follows. (a) Small holes are drilled in a thick $(1 \mathrm{~mm})$ glass slide which serve as inlet(s) and outlet, and a large hole/window is drilled around the region for observation with neutrons. We find that drilling the inlet and outlet holes before the large central one significantly reduces breakages while drilling. This slide will act as a 'reinforcement' for the thinner glass slides (e.g. $t=140 \mu \mathrm{m}$ borosilicate glass slides). A conventional high-speed drill with a diamond drill bit can be employed. (b) A few drops of thiolene (NOA81) are cast onto a thin cover slide and the reinforcement slide is sealed under UV light, any excess adhesive being removed with a razor blade. (c) Holes are drilled through the thin cover slide on the inlet(s) and outlet positions; the thin and thick
I. SANS

(a)

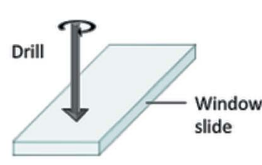

(b)

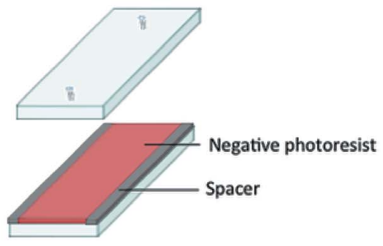

(c) UV $\downarrow^{\downarrow}$

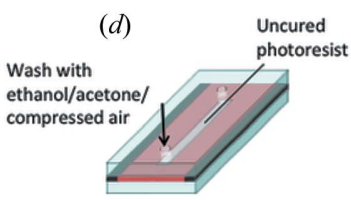

(e)

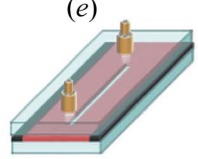

II. SANS/SAXS
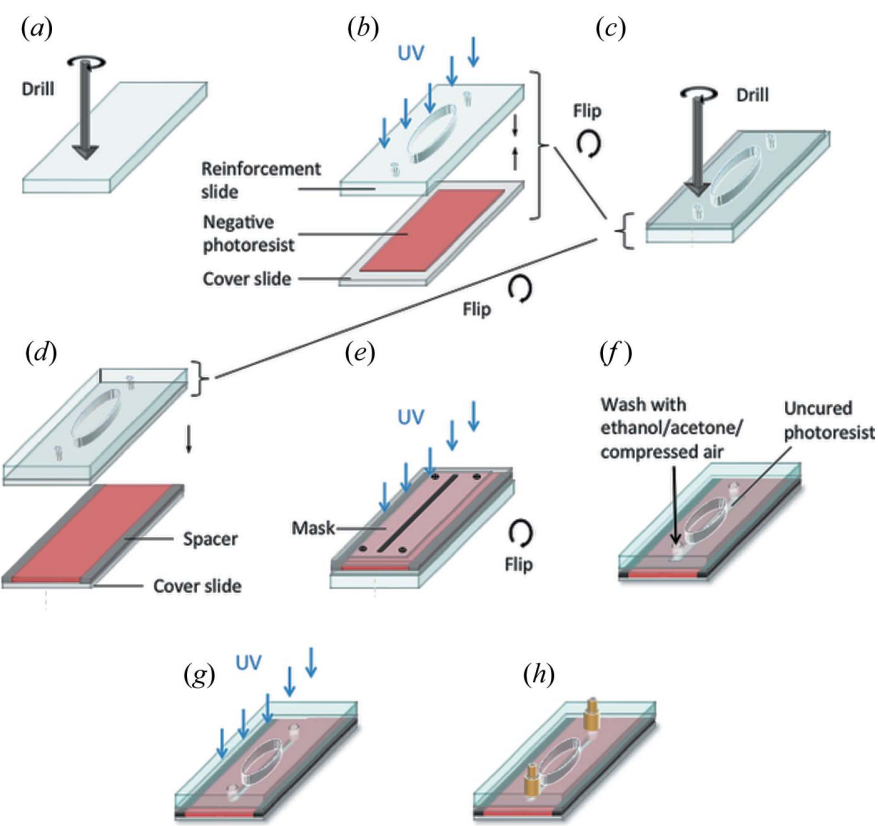

(h)

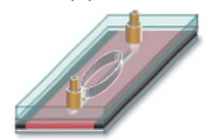

Figure 5

Schematic of microfabrication procedure (method 1) based on a closed-face lithography approach (Cabral et al., 2004; Harrison et al., 2004) and employed in flow-SANS (Lopez et al., 2015). Photopolymerization is carried out between two $\sim 1 \mathrm{~mm}$ (boron-free) glass sheets (left). If a thin ( $\sim 100 \mu \mathrm{m}$ ) slide is used instead, for instance to enable SAXS measurements as well as SANS, the sandwich is reinforced with a thick glass plate to ensure mechanical integrity (right). The channel geometry is imposed by a photomask and development (see text for details). 
slides are then bonded together prior to device patterning. $(d)$ To define a precise channel depth, spacers are placed on top of another thin cover slide, thiolene is poured on top and the reinforced slide sandwiches the thiolene resist layer. (e) The device is flipped, a negative photomask (i.e. with microchannels in black) is placed over the assembly and the whole is exposed to a prescribed UV dose (Cabral et al., 2004) to yield the desired channel depth (e.g. $5 \mathrm{~min}$ at $0.14 \mathrm{~J} \mathrm{~cm}^{-2}$ for a $540 \mu \mathrm{m}$ deep channel). ( $f$ ) The liquid thiolene that remains under the masked sections is flushed out using ethanol, acetone and compressed air. $(g)$ The device is post cured by exposure to high-intensity UV for at least $30 \mathrm{~min}$. (h) Nanoports (or equivalent) are sealed to the device using fast-curing Araldite glue, and the device is ready for operation. The entire process takes approximately $1 \mathrm{~h}$, yielding devices suitable for SANS (Lopez et al., 2015) and SAXS (Poulos et al., 2016).

The minimum feature size obtainable with this method is $\sim 50-100 \mu \mathrm{m}$, depending on the aspect ratio and process parameters (Harrison et al., 2004). Open-face replication methods (Bartolo et al., 2008) or the use of a range of other monomer/polymer resists (Vitale et al., 2015) can further reduce these to a few micrometres. Multi-level patterning of the microchannels is possible by controlling the frontal photopolymerization process of the resist (Cabral et al., 2004; Cabral \& Douglas, 2005).

Overall, this simple lithographic technique yields solventresistant non-deformable microdevices, with transmissions up to $\sim 98 \%$ with quartz windows (or similar with soda lime, crown glass or fused silica). Borosilicate glass has a similarly low background but much lower transmission, and suitable devices must therefore have thin walls $(\sim 2 \times 140 \mu \mathrm{m}$ for $80 \%$ transmission).

\subsection{Method 2: hybrid PDMS-thiolene devices}

While the fabrication of PDMS devices by SU-8 mould replication is well established (Duffy et al., 1998) and enables small scale and densely packed microchannels, the high neutron background and channel deformation under flow of thin PDMS membranes is undesirable. Reinforcement approaches are possible (Martin et al., 2016), but a combination of PDMS and photolithography, illustrated in Fig. 6, appears more attractive. The procedure follows the steps of the previous method until step $(d)$. After the channels have been developed, a replicated PDMS slab (moulded on an SU8 master following the usual procedures; McDonald \& Whitesides, 2002) is oxidized, aligned with the glass ports and irreversibly sealed using a plasma oven, as shown in Figs. 6(e) and $6(f)$. Finally, in step $(g)$ tubing is connected to the PDMS module onto pre-cored ports, and an outlet connector is attached through the reinforcement slide.

The small feature sizes available with PDMS can then be used for fast mixing, formulation or flow processing of complex fluids, allowing the sample to be analysed through a high-quality observation window. With this method it is not possible to carry out truly in situ SANS under flow, as the fluid has to be transported from the PDMS section into the window, which typically has a dead volume of $\sim 1 \mu \mathrm{l}$.

6.3. Method 3: glass devices (etching and bonding, and laser etching)

All-glass devices can offer superior performance compared with methods 1 and 2 in terms of durability and chemical and pressure resistance, which may warrant the higher material and processing costs required. While glass micromachining, etching and bonding (Iliescu et al., 2012) generally involve specialized equipment, a number of commercial suppliers offer a range of devices that seem eminently compatible with microfluidic SANS, provided that a suitable grade of (boronfree) glass is employed. Typically, channels are patterned with use of a masking layer, followed by wet etching with hydrofluoric acid, or dry etching (e.g. with deep reactive-ion etching, DRIE) for high-aspect-ratio channels. Access ports for inlets or outlets can also be wet etched, as well as drilled or sand blasted. Alternative processes couple laser ablation with chemical etching (laser-induced deep etching; http:// www.lpkf.com/applications/lide-technology/). Finally, the patterned surface is bonded by direct bonding or fusion bonding at high ( $~ 923 \mathrm{~K})$ temperatures or with an adhesive, before the fluidic ports are connected. Commercial suppliers often make available robust mounting platforms with push-fit tubing or ferrule connectors for additional robustness (e.g. against leaks or detachment). Typically, these devices can

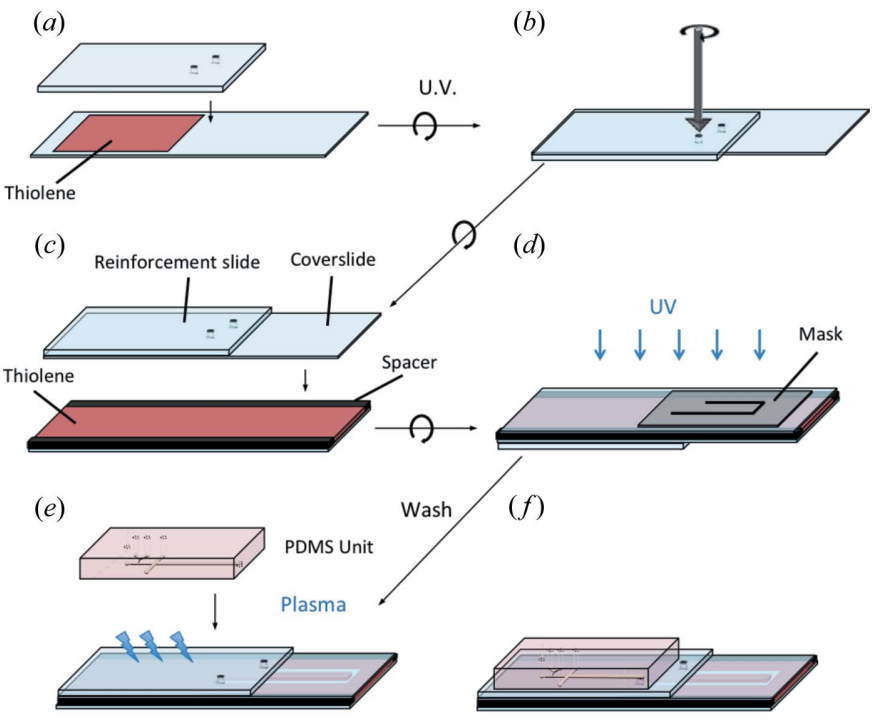

$(g)$

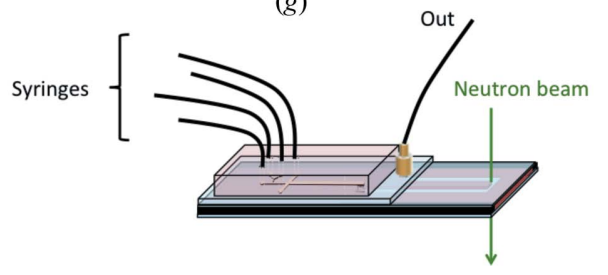

Figure 6

Schematic of PDMS-thiolene hybrid microdevice fabrication (method 2), combining method 1 with PDMS fabrication and sealing to enable higher density and smaller-scale patterning, prior to measurement. 
withstand pressures in excess of 100 bar (and generally limited by the connectors). While borosilicate glass is generally unsuitable because of its high absorption (see Table S1 in the supporting information), a common and inexpensive crown glass (e.g. B270 ultra white glass, Schott AG) with a low boron content is well suited, as demonstrated in previous contrastvariation and phase-mapping experiments (Adamo et al., 2017; Adamo et al., 2018) employing a Dolomite $4 \mathrm{~mm}$ thick microreactor chip (illustrated in Figs. $7 a-7 d$ ).

Selective laser-induced etching methods [see, for instance, LightFab (2018) and Meineke et al. (2016)] are emerging as subtractive three-dimensional printing approaches capable of generating buried microchannels within glass (fused silica and quartz), avoiding the need for glueing or bonding separate sections (Figs. 7e). These typically employ ultrafast pulsed lasers and focusing optics or two-photon processes to pattern directly inside the glass matrix (or, equivalently, within polymeric matrices). The spatial resolution can be as high as $1-$ $2 \mu \mathrm{m}$ and the high optical transparency, chemical, thermal and pressure resistance, and neutron transmission make these approaches particularly suitable for SANS device fabrication.

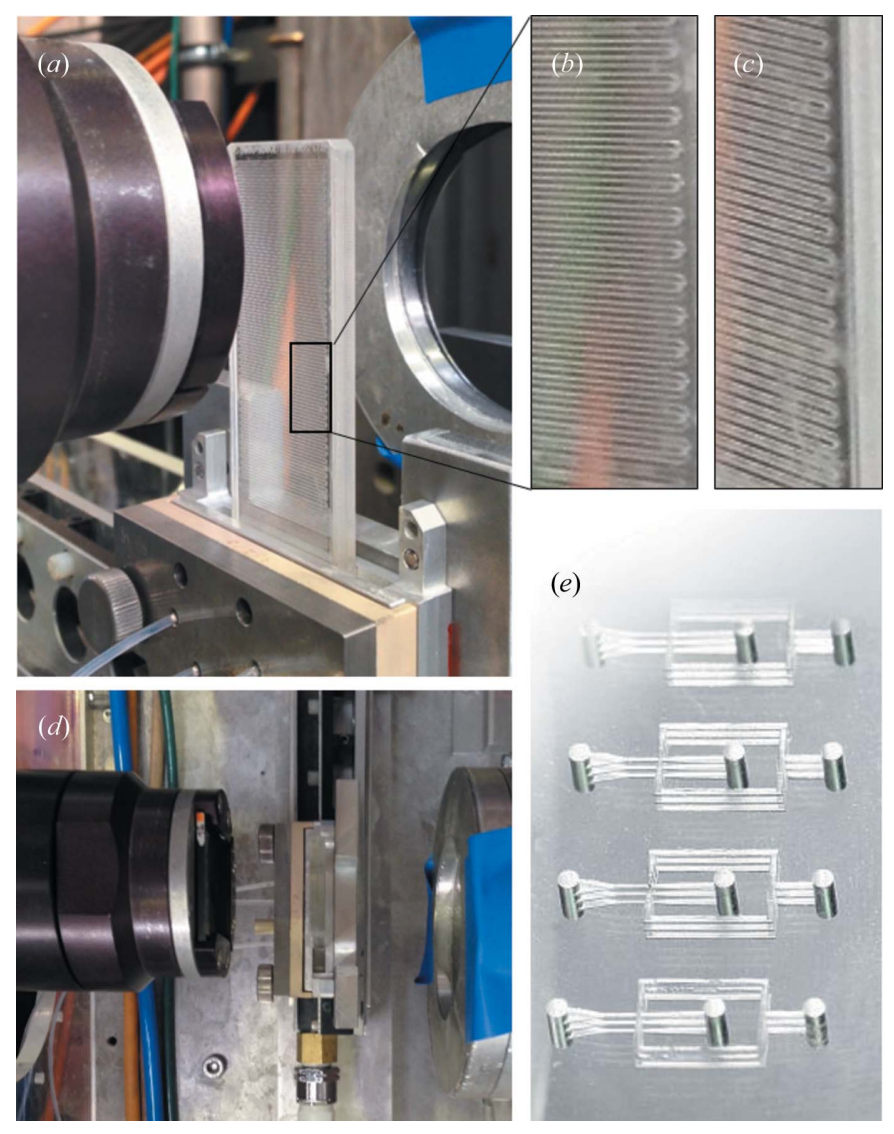

Figure 7

(a) Crown glass chip (Dolomite microreactor) installed on the SANS beamline D22 at ILL, operating in $(b)$ continuous and (c) droplet modes. (d) A top view of the setup, showing the beam and detector tubes. (e) A fused silica microchip fabricated by selective laser etching [reproduced with permission from LightFab (2018), copyright (2018) LightFab GmbH, Aachen, Germany].
6.4. A comparison of existing and emerging microfabrication methods

Table 3 compiles representative microfabrication techniques, along with relevant properties characterizing the SANS quality of the devices and key practical considerations. Evidently, a number of materials and approaches appear suitable for microfluidic SANS, with hydrogenated polymers faring comparatively poorly, especially elastomers such as PDMS. Boron-free glasses (method 3) and metals emerge as good candidates, provided that neutron activation can be kept low, either by material composition or by thin channel walls. While the associated fabrication methods generally involve longer manufacturing times and are more costly than photolithography methods, these generally provide superior longevity, spatial resolution, pressure resistance and, often, SANS quality (in terms of transmission and background scattering).

Methods 1 and 2 proposed here aim to combine the high neutron quality of glass or quartz with the versatility and speed offered by polymer microfabrication. These yield highquality neutron cells that can be manufactured within hours of initial design, albeit suffering from limited resolution (partially overcome by method 2). Their low fabrication cost ( $\sim 10$ USD) and time (of the order of hours) mean that they are effectively disposable and device cleaning might thus not be needed (compared with $\sim 1000$ USD for a commercial glass device, and of the order of weeks for custom manufacturing). Devices fabricated by method 3 using thin (e.g. borosilicate) slides are also compatible with SAXS (which commonly uses thin-walled $\sim 50 \mu \mathrm{m}$ glass capillaries as liquid sample cells).

The advent of facile three-dimensional printing and additive manufacturing of polymers, glasses, metals and ceramics will undoubtedly continue to broaden versatility, lower the cost and increase the speed of rapid prototyping (Bhattacharjee et al., 2016), and are expected to further enable microfluidic SANS. High-precision methods of laser micromachining and etching, which can provide exceptional dimensional control for microdevice fabrication, are becoming increasingly accessible and are well placed to meet SANS requirements.

The varied nature of microfluidic SANS experiments, ranging from flow-SANS and process kinetics to systematic phase-space exploration, will probably require a combination of rapid prototyping and fast iteration, alongside precision manufacturing approaches.

\section{Conclusions}

We have reviewed materials and approaches for the fabrication of microfluidic devices compatible with SANS. A few closed-face photopolymerization methods between quartz (or boron-free glass) plates emerge as effective rapid prototyping approaches, requiring facilities available in most chemical laboratories, and enable rapid iterations that are advantageous for some SANS experiments (e.g. flow-SANS). A number of glass etching and bonding techniques, as well as buried laser etching techniques, provide durable solventcompatible optically transparent high-pressure microdevices 

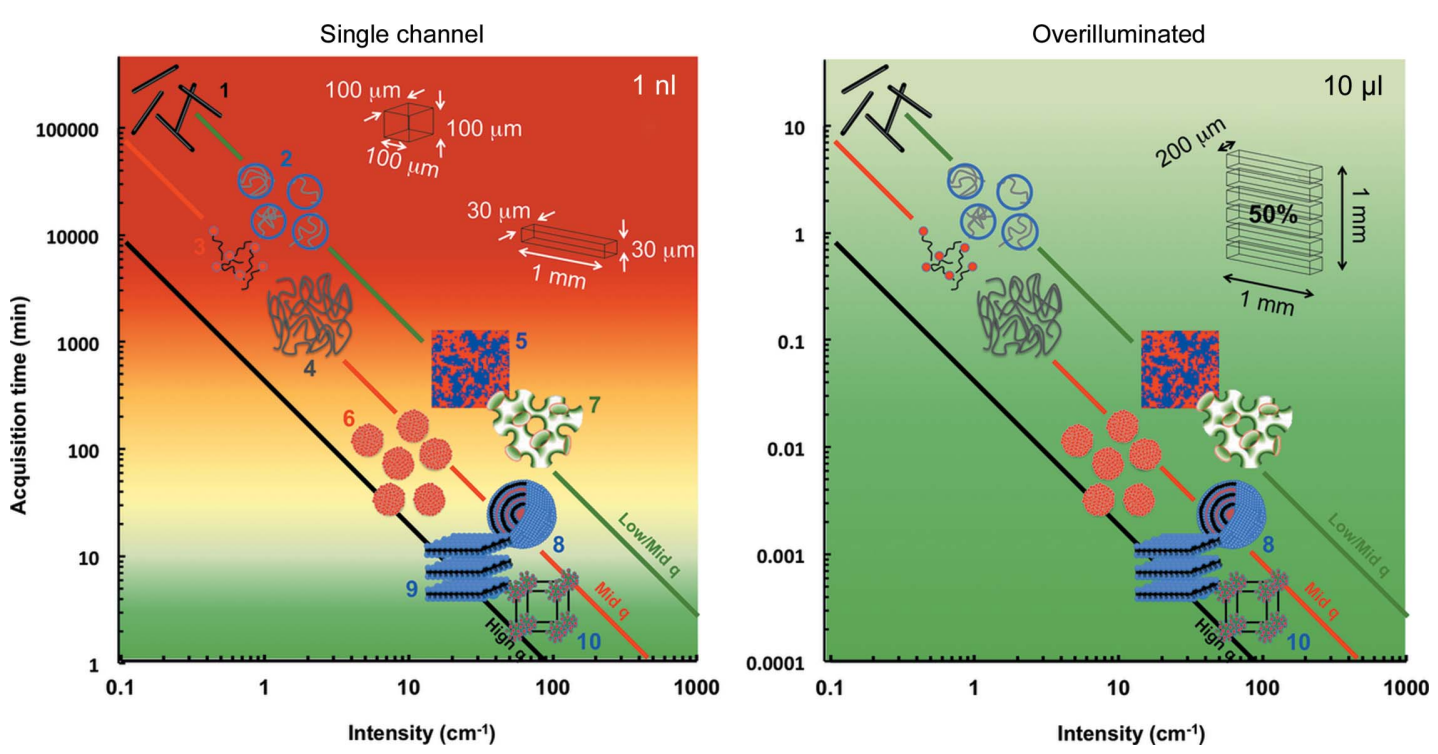

Figure 8

System compatibility with microfluidic SANS. Acquisition times are plotted for representative systems based on their characteristic scattering intensity $\left(\mathrm{cm}^{-1}\right)$, sample volumes of $1 \mathrm{nl}$ and $10 \mu \mathrm{l}$, and the $q$-range/configuration required [defined as high $\left(0.05-0.5 \AA^{-1}\right)$, mid $\left(0.01-0.2 \AA^{-1}\right)$ and mid/low $\left.\left(0.005-0.05 \mathrm{~A}^{-1}\right) q\right]$. Adapted and expanded from Lopez et al. (2015) under a Creative Commons Attribution 4.0 International License, https:// creativecommons.org/licenses/by/4.0/.

that are particularly well suited for microfluidic SANS, in particular for applications requiring prolonged or repeated use (e.g. phase mapping). The combination of both approaches, in addition to continued advances in the threedimensional printing of polymers and glasses, is likely to meet most requirements for microfluidic SANS.

Inevitably, microfluidic approaches reduce the SANS sampling volume, whether by interrogating single microchannels or in flow mapping with a small beam, or by overilluminating several channels, as illustrated in Fig. 1. We therefore conclude with an assessment of the current feasibility of such experiments, based on acquisition times estimated for representative soft-matter systems, $q$ configurations and illuminated volumes, illustrated in Fig. 8. For illustration, we consider (i) a sample volume of $1 \mathrm{nl}$, corresponding to a beam of diameter $\sim 100 \mu \mathrm{m}$ and a channel depth of $100 \mu \mathrm{m}$, representative of a single-channel configuration [see e.g. Lopez et al. (2015) for a volume $\sim 10 \mathrm{nl}$, and (ii) a sample volume of $10 \mu \mathrm{l}$, comparable to the overilluminated channels relevant for phase mapping (Adamo et al., 2017, 2018). We divide the $q$ range accessible in a typical SANS instrument into three representative windows: high $q\left(0.05-0.5 \AA^{-1}\right)$, mid $q\left(0.01-0.2 \AA^{-1}\right)$ and low $q\left(0.005-0.05 \AA^{-1}\right)$. Data acquisition times generally increase towards lower $q$ ranges owing to a combination of a smaller solid angle and/or lower flux for long-wavelength neutrons, making high- and mid- $q$ configurations particularly suitable for microfluidic SANS. Considering the inverse proportionality between acquisition time and both the absolute scattering intensity and (illuminated) sample volume, the experimental feasibility is indicated by colour in Fig. 8, according to the time required per measurement. The boundary between 'feasible' (green) and 'unfeasible' (red) is tentatively set at acquisition times of $\sim 1-10 \mathrm{~min}$ per measurement. For the single-channel setup with $\sim 100 \mu \mathrm{m}$ beams, only concentrated ordered systems are practical in microfluidic SANS with current neutron fluxes. However, $\sim 1 \mathrm{~s}$ acquisitions are often sufficient to determine structural features like a peak position and order parameter, as demonstrated in Fig. 1 $(f)$. For channel overillumination, and beams of the order of centimetres, a large range of systems are compatible with microfluidic phase-mapping SANS. As a rule of thumb, the channel matrix (i.e. the spacing between channels) is $20-50 \%$ of the channel width, channel depths are submillimetre and counting times need to be adjusted accordingly with respect to the bulk sample. Further, operational considerations of the required mixing times and flow dispersion, relevant for the precise formulation of mixtures, must be carefully considered (Adamo et al., 2017).

Overall, microfluidics offers unprecedented opportunities to expedite traditional SANS experiments (e.g. phase-space exploration) or to unlock the molecular or mesoscopic underpinnings of complex fluid rheology and processing, and the mechanisms and kinetics of phase and conformation transition kinetics, amongst others. This review provides clear recommendations for choice of materials and fabrication methods for microfluidic SANS.

\section{Related literature}

For further literature related to the supporting information, see Brûlet et al. (2007), Dolník et al. (2000), Glinka (2011), Hammouda (2008), James \& Doremus (2008), Lide (2003), NIST (2018), Osman et al. (2015), Prince et al. (1999), Root et al. (1989) and Sears (1992).

\section{Acknowledgements}

We thank the Institut Laue-Langevin (ILL, Grenoble, France, project LTP-9-6; http://doi.ill.fr/10.5291/ILL-DATA.LTP-9-6) 
and ISIS (Oxfordshire, UK) for beamtime, and the Partnership for Soft Condensed Matter (PSCM, ILL) for support. Data are available on request; please contact polymermicrofluidics@imperial.ac.uk.

\section{Funding information}

We acknowledge financial support from the Engineering and Physical Sciences Research Council (EPSRC) (EP/L020564/1) and the Royal Society (UK).

\section{References}

Adamo, M., Poulos, A. S., Lopez, C. G., Martel, A., Porcar, L. \& Cabral, J. T. (2018). Soft Matter, 14, 1759-1770.

Adamo, M., Poulos, A., Miller, R. M., Lopez, C. G., Martel, A., Porcar, L. \& Cabral, J. T. (2017). Lab Chip, 17, 1559-1569.

Adams, D. P., Vasile, M. J., Benavides, G. \& Campbell, A. N. (2001). Precision Eng. 25, 107-113.

Bailey, I. (2003). Z. Kristallogr. Cryst. Mater. 218, 84-95.

Barker, J. G. \& Mildner, D. F. R. (2015). J. Appl. Cryst. 48, 1055-1071.

Barrett, R., Faucon, M., Lopez, J., Cristobal, G., Destremaut, F., Dodge, A., Guillot, P., Laval, P., Masselon, C. \& Salmon, J.-B. (2006). Lab Chip, 6, 494-499.

Bartolo, D. \& Aarts, D. G. (2012). Soft Matter, 8, 10530-10535.

Bartolo, D., Degré, G., Nghe, P. \& Studer, V. (2008). Lab Chip, 8, 274 279.

Becker, H. \& Dietz, W. (1998). Proc. SPIE, 3515, 177-181.

Becker, H. \& Gärtner, C. (2008). Anal. Bioanal. Chem. 390, 89-111.

Becker, H. \& Heim, U. (2000). Sensors Actuators A Phys. 83, 130-135

Bélanger, M.-C. \& Marois, Y. (2001). J. Biomed. Mater. Res. 58, 467477.

Bent, J., Hutchings, L., Richards, R., Gough, T., Spares, R., Coates, P. D., Grillo, I., Harlen, O., Read, D., Graham, R., Likhtman, A., Groves, D. J., Nicholson, T. M. \& McLeish, T. C. B. (2003). Science, 301, 1691-1695.

Bent, J. F., Richards, R. W. \& Gough, T. D. (2003). Rev. Sci. Instrum. 74, 4052-4057.

Beuvier, T., Panduro, E. A. C., Kwaśniewski, P., Marre, S., Lecoutre, C., Garrabos, Y., Aymonier, C., Calvignac, B. \& Gibaud, A. (2015). Lab Chip, 15, 2002-2008.

Bhattacharjee, N., Urrios, A., Kang, S. \& Folch, A. (2016). Lab Chip, 16, 1720-1742.

Brennich, M. E., Nolting, J.-F., Dammann, C., Nöding, B., Bauch, S., Herrmann, H., Pfohl, T. \& Köster, S. (2011). Lab Chip, 11, 708-716.

Bretagne, A., Cotot, F., Arnaud-Roux, M., Sztucki, M., Cabane, B. \& Galey, J.-B. (2017). Soft Matter, 13, 3812-3821.

Brûlet, A., Lairez, D., Lapp, A. \& Cotton, J.-P. (2007). J. Appl. Cryst. 40, 165-177.

Cabral, J. T. \& Douglas, J. F. (2005). Polymer, 46, 4230-4241.

Cabral, J. T., Hudson, S. D., Harrison, C. \& Douglas, J. F. (2004). Langmuir, 20, 10020-10029.

Catalano, R., Perozziello, G., Simone, G., Candeloro, P., Gentile, F., Coluccio, M. L., Pardeo, F., Burghammer, M., Cuda, G., Riekel, C. \& Di Fabrizio, E. (2014). Microelectron. Eng. 124, 13-16.

Chandrasekaran, S., Brazzle, J. D. \& Frazier, A. B. (2003). J. Microelectromech. Syst. 12, 281-288.

Cloke, V. M., Higgins, J. S., Phoon, C. L., Richardson, S. M., King, S. M., Done, R. \& Cooper, T. E. (1996). Rev. Sci. Instrum. 67, 31583163.

Cummins, P., Staples, E., Millen, B. \& Penfold, J. (1990). Meas. Sci. Technol. 1, 179-183.

Cygan, Z. T., Cabral, J. T., Beers, K. L. \& Amis, E. J. (2005). Langmuir, 21, 3629-3634.
Dhouib, K., Khan Malek, C., Pfleging, W., Gauthier-Manuel, B., Duffait, R., Thuillier, G., Ferrigno, R., Jacquamet, L., Ohana, J., Ferrer, J.-L., Théobald-Dietrich, A., Giegé, R., Lorber, B. \& Sauter, C. (2009a). Lab Chip, 9, 1412-1421.

Dittrich, P. S., Tachikawa, K. \& Manz, A. (2006). Anal. Chem. 78, 3887-3908.

Dolník, V., Liu, S. \& Jovanovich, S. (2000). Electrophoresis, 21, 41-54.

Dootz, R., Evans, H., Köster, S. \& Pfohl, T. (2007). Small, 3, 96-100.

Duffy, D. C., McDonald, J. C., Schueller, O. J. \& Whitesides, G. M. (1998). Anal. Chem. 70, 4974-4984.

Eberle, A. P. \& Porcar, L. (2012). Curr. Opin. Colloid Interface Sci. 17, 33-43.

Egres, R. G., Nettesheim, F. \& Wagner, N. J. (2006). J. Rheol. 50, 685709.

Evans, H., Dootz, R., Köster, S., Struth, B. \& Pfohl, T. (2007). Bull. Pol. Acad. Sci. Tech. Sci. 55, 217-227.

Focke, M., Kosse, D., Müller, C., Reinecke, H., Zengerle, R. \& von Stetten, F. (2010). Lab Chip, 10, 1365-1386.

Gentile, L., Rossi, C. O., Olsson, U. \& Ranieri, G. A. (2011). Langmuir, 27, 2088-2092.

Ghazal, A., Lafleur, J. P., Mortensen, K., Kutter, J. P., Arleth, L. \& Jensen, G. V. (2016). Lab Chip, 16, 4263-4295.

Glinka, C. J. (2011). J. Appl. Cryst. 44, 618-624.

Golonka, L. J., Zawada, T., Radojewski, J., Roguszczak, H. \& Stefanow, M. (2006). Int. J. Appl. Ceram. Technol. 3, 150-156.

Gómez-de Pedro, S., Puyol, M. \& Alonso-Chamarro, J. (2010). Nanotechnology, 21, 415603.

Goral, V. N., Hsieh, Y.-C., Petzold, O. N., Faris, R. A. \& Yuen, P. K. (2010). J. Micromech. Microeng. 21, 017002.

Graceffa, R., Nobrega, R. P., Barrea, R. A., Kathuria, S. V., Chakravarthy, S., Bilsel, O. \& Irving, T. C. (2013). J. Synchrotron Rad. 20, 820-825.

Greaves, E. D. \& Manz, A. (2005). Lab Chip, 5, 382-391.

Grillo, I. (2009). Curr. Opin. Colloid Interface Sci. 14, 402-408.

Gurnon, A. K., Godfrin, P. D., Wagner, N. J., Eberle, A. P., Butler, P. \& Porcar, L. (2014). J. Visualized Exp. 84, 51068.

Hammouda, B. (2008). Probing Nanoscale Structures: the SANS Toolbox. NIST Center for Neutron Research, Gaithersburg, Maryland, USA. https://www.ncnr.nist.gov/staff/hammouda/ the_sans_toolbox.pdf

Harrison, C., Cabral, J. T., Stafford, C. M., Karim, A. \& Amis, E. J. (2004). J. Micromech. Microeng. 14, 153-158.

Hayward, D. W., Chiappisi, L., Prévost, S., Schweins, R. \& Gradzielski, M. (2018). Sci. Rep. 8, 7299.

Heckele, M. \& Schomburg, W. (2003). J. Micromech. Microeng. 14, R1.

Hudson, S. D., Phelan, F. R. Jr, Handler, M. D., Cabral, J. T., Migler, K. B. \& Amis, E. J. (2004). Appl. Phys. Lett. 85, 335-337.

Iliescu, C., Taylor, H., Avram, M., Miao, J. \& Franssila, S. (2012). Biomicrofluidics, 6, 016505.

Imae, T., Kanaya, T., Furusaka, M. \& Torikai, N. (2011). Neutrons in Soft Matter. Chichester: John Wiley and Sons.

James, F. \& Doremus, R. (2008). Ceramic and Glass Materials: Structure, Properties and Processing. London: Springer.

Jones, W. K., Liu, Y., Larsen, B., Wang, P. \& Zampino, M. (2000). Int. J. Microcircuits Electron. Packag. 23, 469-473.

Jordan, A., Jacques, M., Merrick, C., Devos, J., Forsyth, V. T., Porcar, L. \& Martel, A. (2016). J. Appl. Cryst. 49, 2015-2020.

Kalus, J., Neubauer, G. \& Schmelzer, U. (1990). Rev. Sci. Instrum. 61, 3384-3389.

Khoury, C., Mensing, G. A. \& Beebe, D. J. (2002). Lab Chip, 2, 50-55.

Kobayashi, I., Wada, Y., Uemura, K. \& Nakajima, M. (2008). Microfluid Nanofluid, 5, 677-687.

Koester, S. \& Pfohl, T. (2012). Mod. Phys. Lett. B, 26, 1230018.

Lang, P., Neiß, S. \& Woias, P. (2011). J. Micromech. Microeng. 21, 125024.

Lee, J. N., Park, C. \& Whitesides, G. M. (2003). Anal. Chem. 75, 65446554. 
Lee, J. S., Dylla-Spears, R., Teclemariam, N. P. \& Muller, S. J. (2007). Appl. Phys. Lett. 90, 074103.

Lee, S.-J. J. \& Sundararajan, N. (2010). Microfabrication for Microfluidics. Norwood: Artech House.

Liberatore, M. W., Nettesheim, F., Wagner, N. J. \& Porcar, L. (2006). Phys. Rev. E, 73, 020504.

Lide, D. R. (2003). CRC Handbook of Chemistry and Physics, 84th ed. Boca Raton: CRC Press.

LightFab (2018). Three-Dimensional Microfluidics, http://www. lightfab.de.

Lin, Y.-S., Yang, C.-H., Wang, C.-Y., Chang, F.-R., Huang, K.-S. \& Hsieh, W.-C. (2012). Sensors, 12, 1455-1467.

Lindner, P. \& Oberthür, R. (1984). Rev. Phys. Appl. (Paris), 19, 759763.

Lopez, C. G., Watanabe, T., Martel, A., Porcar, L. \& Cabral, J. T. (2015). Sci. Rep. 5, 7727.

Lutz-Bueno, V., Kohlbrecher, J. \& Fischer, P. (2015). J. Non-Newt. Fluid Mech. 215, 8-18.

Lutz-Bueno, V., Zhao, J., Mezzenga, R., Pfohl, T., Fischer, P. \& Liebi, M. (2016). Lab Chip, 16, 4028-4035.

Marmiroli, B. \& Amenitsch, H. (2012). Eur. Biophys. J. 41, 851-861.

Martin, H. P., Brooks, N. J., Seddon, J. M., Luckham, P. F., Terrill, N. J., Kowalski, A. J. \& Cabral, J. T. (2016). Soft Matter, 12, 1750-1758.

McDonald, J. C. \& Whitesides, G. M. (2002). Acc. Chem. Res. 35, 491499.

Meineke, G., Hermans, M., Klos, J., Lenenbach, A. \& Noll, R. (2016). Lab Chip, 16, 820-828.

Merlin, A., Angly, J., Daubersies, L., Madeira, C., Schöder, S., Leng, J. \& Salmon, J.-B. (2011). Eur. Phys. J. E, 34, 58.

Metwally, K., Robert, L., Queste, S., Gauthier-Manuel, B. \& KhanMalek, C. (2012). Microsyst Technol. 18, 199-207.

Metze, M., Barbe, S., Reiche, A., Kesting, A. \& Schweins, R. (2017). J. Neutron Res. 19, 177-185.

Mildner, D. F. R. (2014). J. Appl. Cryst. 47, 1247-1251.

Møller, M., Nielsen, S. S., Ramachandran, S., Li, Y., Li, Y., Tria, G., Streicher, W., Petoukhov, M. V., Cerione, R. A., Gillilan, R. E. \& Vestergaard, B. (2013). PLoS One, 8, e74783.

NIST (2017). Neutron Activation and Scattering Calculator. https:// www.ncnr.nist.gov/resources/activation. NIST, Maryland, USA.

NIST (2018). Neutron Scattering Lengths and Cross Sections. https:// www.ncnr.nist.gov/resources/n-lengths. NIST, Maryland, USA.

Norman, A. I., Zhang, W., Beers, K. L. \& Amis, E. J. (2006). J. Colloid Interface Sci. 299, 580-588.

Osman, A., El-Sarraf, M., Abdel-Monem, A. \& Abdo, A. E.-S. (2015). Ann. Nucl. Energy, 78, 146-151.

Papautsky, I., Brazzle, J., Swerdlow, H. \& Frazier, A. B. (1998). J. Microelectromech. Syst. 7, 267-273.

Penfold, J., Staples, E., Tucker, I., Carroll, P., Clayton, I., Cowan, J., Lawton, G., Amin, S., Ferrante, A. \& Ruddock, N. (2006). J. Phys. Chem. B, 110, 1073-1082.

Pham, N., Radajewski, D., Round, A., Brennich, M., Pernot, P., Biscans, B., Bonneté, F. \& Teychené, S. (2017). Anal. Chem. 89, 2282-2287.

Pollack, L. \& Doniach, S. (2009). Methods Enzymol. 469, 253-268.

Poulos, A. S., Nania, M., Lapham, P., Miller, R. M., Smith, A. J., Tantawy, H., Caragay, J., Gummel, J., Ces, O., Robles, E. S. J. \& Cabral, J. T. (2016). Langmuir, 32, 5852-5861.

Prince, E., Wilson, A. J. C., Hahn, T. \& Shmueli, U. (1999). International Tables for Crystallography, Vol. C, Mathematical, Physical and Chemical Tables, ch. 2.6. Dordrecht: Kluwer.

Qazi, S. J. S., Rennie, A. R., Tucker, I., Penfold, J. \& Grillo, I. (2011). J. Phys. Chem. B, 115, 3271-3280.

Rodriguez, M. A., Yang, P., Kotula, P. \& Dimos, D. (2000). Adv. X-ray Anal. 43, 332-337.
Rodríguez-Ruiz, I., Radajewski, D., Charton, S., Phamvan, N., Brennich, M., Pernot, P., Bonneté, F. \& Teychené, S. (2017). Sensors, 17, 1266.

Root, J. H., Buyers, W. J., Page, J. H., Schaefer, D. W. \& Brinker, C. (1989). MRS Proc. 166, 379.

Schindler, K. \& Roosen, A. (2009). J. Eur. Ceram. Soc. 29, 899904.

Schwemmer, F., Blanchet, C. E., Spilotros, A., Kosse, D., Zehnle, S., Mertens, H. D., Graewert, M. A., Rössle, M., Paust, N., Svergun, D. I., von Stetten, F., Zengerle, R. \& Mark, D. (2016). Lab Chip, 16, $1161-1170$

Sears, V. F. (1992). Neutron News, 3(3), 26-37.

Sharma, J., King, S. M., Bohlin, L. \& Clarke, N. (2010). Nucl. Instrum. Methods Phys. Res. A, 620, 437-444.

Shastry, M., Luck, S. D. \& Roder, H. (1998). Biophys. J. 74, 27142721.

Shibayama, M., Nagao, M., Okabe, S. \& Karino, T. (2005). J. Phys. Soc. Jpn, 74, 2728-2736.

Shin, E., Choi, S.-H., Seong, B.-S., Lee, H.-C. \& Lee, K. (2010). Appl. Phys. A, 99, 621-625.

Silva, B. F. (2017). Phys. Chem. Chem. Phys. 19, 23690-23703.

Skou, M., Skou, S., Jensen, T. G., Vestergaard, B. \& Gillilan, R. E. (2014). J. Appl. Cryst. 47, 1355-1366.

Sollier, E., Murray, C., Maoddi, P. \& Di Carlo, D. (2011). Lab Chip, 11, 3752-3765.

Squires, T. M. \& Quake, S. R. (2005). Rev. Mod. Phys. 77, 977-1026.

Stehle, R., Goerigk, G., Wallacher, D., Ballauff, M. \& Seiffert, S. (2013). Lab Chip, 13, 1529-1537.

Takeda, M., Kusano, T., Matsunaga, T., Endo, H., Shibayama, M. \& Shikata, T. (2011). Langmuir, 27, 1731-1738.

Tepe, T., Schulz, M., Zhao, J., Tirrell, M., Bates, F., Mortensen, K. \& Almdal, K. (1995). Macromolecules, 28, 3008-3011.

Toft, K. N., Vestergaard, B., Nielsen, S. S., Snakenborg, D., Jeppesen, M. G., Jacobsen, J. K., Arleth, L. \& Kutter, J. P. (2008). Anal. Chem. 80, 3648-3654.

Tong, J., Nakajima, M., Nabetani, H., Kikuchi, Y. \& Maruta, Y. (2001). J. Colloid Interface Sci. 237, 239-248.

Trebbin, M., Steinhauser, D., Perlich, J., Buffet, A., Roth, S. V., Zimmermann, W., Thiele, J. \& Förster, S. (2013). Proc. Natl Acad. Sci. USA, 110, 6706-6711.

Tsao, C.-W., Chen, T.-Y., Woon, W. Y. \& Lo, C.-J. (2012). Microsyst. Technol. 18, 713-722.

Vasudevan, M., Buse, E., Lu, D., Krishna, H., Kalyanaraman, R., Shen, A. Q., Khomami, B. \& Sureshkumar, R. (2010). Nat. Mater. 9, 436-441.

Vitale, A., Hennessy, M. G., Matar, O. K. \& Cabral, J. T. (2015). Adv. Mater. 27, 6118-6124.

Weston, J. S., Seeman, D. P., Blair, D. L., Salipante, P. F., Hudson, S. D. \& Weigandt, K. M. (2018). Rheol. Acta, 57, 241-250.

Whitesides, G. M. (2006). Nature, 442, 368-373.

With, S., Trebbin, M., Bartz, C. B., Neuber, C., Dulle, M., Yu, S., Roth, S. V., Schmidt, H.-W. \& Förster, S. (2014). Langmuir, 30, 12494 12502.

Yearley, E. J., Sasa, L. A., Welch, C. F., Taylor, M. A., Kupcho, K. M., Gilbertson, R. D. \& Hjelm, R. P. (2010). Rev. Sci. Instrum. 81, 045109.

Yoo, M., Ogle, J., Borie, B., Lee, E. \& Hendricks, R. (1982). Acta Metall. 30, 1733-1742.

Zhang, Y., Bottausci, F., Rao, M. P., Parker, E., Mezic, I. \& Macdonald, N. (2008). Biomed. Microdevices, 10, 509-517.

Zheng, B., Roach, L. S. \& Ismagilov, R. F. (2003). J. Am. Chem. Soc. 125, 11170-11171.

Zhou, X., Li, J., Wu, C. \& Zheng, B. (2008). Macromol. Rapid Commun. 29, 1363-1367. 